\title{
Interferon lambda in inflammation and autoimmune rheumatic diseases
}

Rishi R. Goel(10 ${ }^{1,2}$, Sergei V. Kotenko $0^{3}$ and Mariana J. Kaplan (10 ${ }^{1 凶}$

Abstract | Interferons are potent antiviral cytokines that modulate immunity in response to infection or other danger signals. In addition to their antiviral functions, type I interferons (IFNa and IFN $\beta$ ) are important in the pathogenesis of autoimmune diseases. Type III interferons (IFN $\lambda \mathrm{s}$ ) were initially described as a specialized system that inhibits viral replication at epithelial barrier surfaces while limiting inflammatory damage. However, evidence now suggests that type III interferons have complex effects on both innate and adaptive immune responses and might also be pathogenic in systemic autoimmune diseases. Concentrations of IFN $\lambda$ s are increased in blood and tissues in a number of autoimmune rheumatic diseases, including systemic lupus erythematosus, and are further associated with specific clinical and laboratory parameters. This Review is aimed at providing a critical evaluation of the current literature on IFN $\lambda$ biology and how type III interferons might contribute to immune dysregulation and tissue damage in autoimmunity. The potential effects of type III interferons on treatment strategies for autoimmune rheumatic diseases, such as interferon blockade, are also considered.

'Systemic Autoimmunity Branch, National Institute of Arthritis and Musculoskeletal and Skin Diseases, National Institutes of Health, Bethesda, MD, USA.

${ }^{2}$ Institute for Immunology, Perelman School of Medicine, University of Pennsylvania, Philadelphia, PA, USA.

${ }^{3}$ Department of Microbiology, Biochemistry and Molecular Genetics, Center for Cell Signaling, Center for Immunity and Inflammation, Rutgers New Jersey Medical School, Newark, NJ, USA.

凶e-mail:rishi.goel@ pennmedicine.upenn.edu; mariana.kaplan@nih.gov

https://doi.org/10.1038/ s41584-021-00606-1
Interferons are a group of cytokines that are produced in response to infection or other inflammatory stimuli. Functionally, these cytokines have potent antiviral effects and modulate immune cell function. Interferons are classified into three subgroups: type I interferons (IFNa, IFN $\beta$, IFN $\varepsilon$, IFNא and IFN $\omega$ ), type II interferon (IFN $\gamma$ ) and type III interferons (four IFN $\lambda$ subtypes). The type III interferons are a relatively new addition to the interferon family and are especially important in immune defence at barrier surfaces ${ }^{1-3}$. Although type III interferons are structurally distinct from type I interferons, they have overlapping functions, and both signal through the Janus kinase (JAK)-signal transducer and activator of transcription (STAT) pathway to induce transcription of interferon-stimulated genes (ISGs) and promote antiviral activity.

Interferons are critical for host defence, but can also contribute to disease processes in autoimmune and inflammatory diseases. Indeed, dysregulated type I interferon responses are a major feature of systemic lupus erythematosus (SLE) and a number of other systemic autoimmune diseases ${ }^{4}$. Mutations in genes associated with the type I interferon pathway can also result in monogenic autoinflammatory diseases ${ }^{5,6}$. Chronic activation of the type I interferon system has myriad effects on both innate and adaptive immune responses. For example, type I interferons can modulate antigen-presenting cell (APC) function, promote B cell activation and antibody production, and induce the production of chemokines that lead to tissue inflammation ${ }^{7}$.
Given the importance of this pathway, biologic agents that target either IFNa or IFNa receptor (IFNAR), the main receptor for type I interferons, have emerged as a potential therapeutic strategy for systemic rheumatic diseases such as $\mathrm{SLE}^{8}$. However, some of these agents have had mixed efficacy in clinical trials, highlighting the complexity and heterogeneity of immune derangement in systemic autoimmunity.

In addition to type I interferons, type III interferons might also contribute to autoimmune and chronic inflammatory diseases. Although type III interferons were initially described as an anti-inflammatory counterpart to the type I interferon system, data suggest that IFN $\lambda$ biology is more complex than suspected and that excessive and chronic activation of the IFN $\lambda$ pathway can in fact be detrimental to the host. In this Review, we summarize new insights into IFN $\lambda$ biology and how type III interferons compare with the type I interferon system. We also discuss potential roles for type III interferons in the immunopathology of systemic rheumatic diseases and explore how this information can be applied to current and future treatment strategies.

\section{IFN $\lambda$ biology and signalling}

Four subtypes of IFN $\lambda$ have been identified in humans: IFN $\lambda 1$ (IL-29), IFN $\lambda 2$ (IL-28A), IFN $\lambda 3$ (IL-28B) and IFN $\lambda$ 4. Several IFNL pseudogenes are located in the vicinity of the genes encoding IFN $\lambda$ s $1-3$ (REF. $\left.{ }^{9}\right)$, and a common dinucleotide polymorphism in the IFNL locus can result in a frameshift mutation that enables the 


\section{Key points \\ - Type III interferons (IFN $\lambda s$ ) are critical for immune defence against pathogens at epithelial barrier surfaces and were initially described as an anti-inflammatory counterpart to the type I interferon system. \\ - IFN $\lambda$ s have complex effects on both innate and adaptive immunity and can promote inflammation in certain contexts. \\ - Similar to type I interferons, type III interferon concentrations are increased in the blood and affected tissues of patients with autoimmune rheumatic diseases such as systemic lupus erythematosus (SLE). \\ - Concentrations of IFN $\lambda$ s correlate with clinical and immunological parameters and seem to have non-redundant effects on cell-specific and tissue-specific disease processes in SLE. \\ - Current biologic therapies that target IFNa or its receptor do not block the effects of IFN $\lambda$ s. \\ - Additional research is needed to fully characterize the context-dependent effects of IFN $\lambda$ s and to optimize treatment for patients with autoimmune rheumatic diseases.}

expression of a functional IFNL4 gene product ${ }^{10}$. In contrast to humans, only IFN $\lambda 2$ and IFN $\lambda 3$ are expressed in mice $^{11}$.

IFN $\lambda$ s signal through a unique heterodimeric receptor complex comprising IFN $\lambda$ receptor 1 (IFNLR1) and IL-10 receptor subunit- $\beta^{12,13}$. An important difference between type I and type III interferons is the expression of their respective receptor complexes. IFNAR is widely expressed on almost all cell types in the body, whereas expression of the IFN $\lambda$ receptor (IFNLR) is more limited, being highly expressed on epithelial cells and some immune cells, such as neutrophils in mice and B cells in humans ${ }^{1-3}$. This distribution enables the IFN $\lambda$ system to have specialized effects at barrier sites.

In target cells, the IFNLR complex signals through the JAK-STAT pathway (FIG. 1). IFNa, IFN $\beta$ and IFN $\lambda$ s can all activate JAK1 and non-receptor tyrosine-protein kinase TYK2, resulting in the phosphorylation of STAT proteins and the formation of STAT1-STAT2 heterodimers ${ }^{1-3}$. Interferon regulatory factor 9 (IRF9) interacts with these STAT1-STAT2 heterodimers to form the interferon stimulated gene factor 3 (ISGF3) transcription factor complex. ISGF3 then translocates to the nucleus, where it can bind to interferon-stimulated regulatory element sequences located in the promoters of ISGs such as MX1, IFIT1 and ISG15 (REF. ${ }^{14}$ ).

Although type I and type III interferons share downstream signalling machinery, some differences exist in the kinetics of different types of interferon responses. Type III interferons induce longer-lasting expression of ISGs at lower amplitude than type I interferons ${ }^{15,16}$. This difference might be caused by differential negative regulation by Ubl carboxyl-terminal hydrolase 18 , which preferentially inhibits type I interferon signalling but not type III interferon signalling ${ }^{17-19}$. Nevertheless, the transcriptional profiles induced by type I interferons and type III interferons are remarkably similar, and a unique signature for IFN $\lambda$ s has not been identified. Despite these similarities, studies in IFNLR-deficient $\left(\right.$ Ifnlr $\left.{ }^{-/-}\right)$mice indicate that IFN $\lambda$ s have non-redundant functions in immunity and that type III interferons are particularly important for immune responses at mucosal surfaces $^{20-25}$
Current thinking suggests that IFN $\lambda$ s restrict viral replication in epithelial cells without inducing inflammatory patholog $y^{26}$. One potential mechanism for the non-inflammatory effects of type III interferons compared with type I interferons is related to chemokine production. IFN $\beta$ induces the expression of the chemokines CXCL9, CXCL10 and CXCL11 to a greater extent than IFN $\lambda$ s, owing to insufficient induction of IRF1 by IFN $\lambda s^{27}$. These chemokines can recruit CXCR3 ${ }^{+}$leukocytes and are important in the development of tissue inflammation. IFN $\beta$ promotes the formation of STAT1 homodimers that bind to the IRF1 promoter and induce IRF1 expression (FIG. 1). By contrast, IFN $\lambda$ s do not induce sufficient IRF1 expression to enable the production of chemokines. Notably, IRF1 induction is dependent on the expression of IFNLR1, as overexpression of IFNLR1 increases the amount of CXC chemokines produced in response to IFN $\lambda$ s to similar levels to those elicited by IFN $\beta$. These findings ${ }^{27}$ suggest that IFNLR1 density is an important determinant of IFN $\lambda$ function. As such, IFN $\lambda$ s could theoretically promote inflammation if IFNLR1 expression is sufficiently high to induce IRF1 expression. The way in which IFNLR1 expression is regulated, particularly in autoimmune diseases, might therefore explain the context-dependent effects of IFN $\lambda$ s (discussed in the following sections).

IFN $\lambda$ s can also signal through a variety of noncanonical mechanisms. Data from mouse neutrophils show that IFN $\lambda$ s can activate JAK2 and inhibit reactive oxygen species (ROS) production in a model of intestinal inflammation ${ }^{28}$. This effect was not mediated through traditional STAT1-dependent signal transduction but rather through JAK2-mediated inhibition of RAC-alpha serine/threonine-protein kinase (AKT). Whether this JAK2-AKT pathway is present and operational in other cell types is currently unclear. IFN $\lambda$ s can also activate the mitogen-activated protein kinase pathway ${ }^{29}$ and modulate cell-cell tight junctions $s^{30}$, further highlighting the complexity of their biology.

\section{IFN $\lambda$ s in host immunity}

IFN $\lambda$ s have direct effects on epithelial cells, inducing a variety of cell-intrinsic mechanisms that restrict viral replication and inhibit viral transmission ${ }^{26}$. However, evidence indicates that IFN $\lambda$ s have additional functions in orchestrating innate and adaptive immune responses. These functions can be separated into direct effects on IFN $\lambda$-responsive cells (TABLE 1) and indirect effects on nonresponsive cell types. The effects of IFN $\lambda$ s on different cell types have been reviewed elsewhere ${ }^{3,31}$. In this section, we focus specifically on aspects of the IFN $\lambda$ response axis that are relevant for inflammation and autoimmunity.

Innate immunity. IFN $\lambda$ s have direct effects on various innate immune cell populations (TABLE 1). Multiple studies report that IFN $\lambda$ s can activate mouse neutrophils to induce STAT1 phosphorylation and ISG expression ${ }^{25,28,32}$. IFN $\lambda$ s can also increase ROS production by mouse neutrophils, and in vivo experiments show that mice with neutrophil-specific deletion of Ifnlr 1 are more susceptible to Aspergillus infection ${ }^{33}$, indicating that IFN $\lambda$ s 


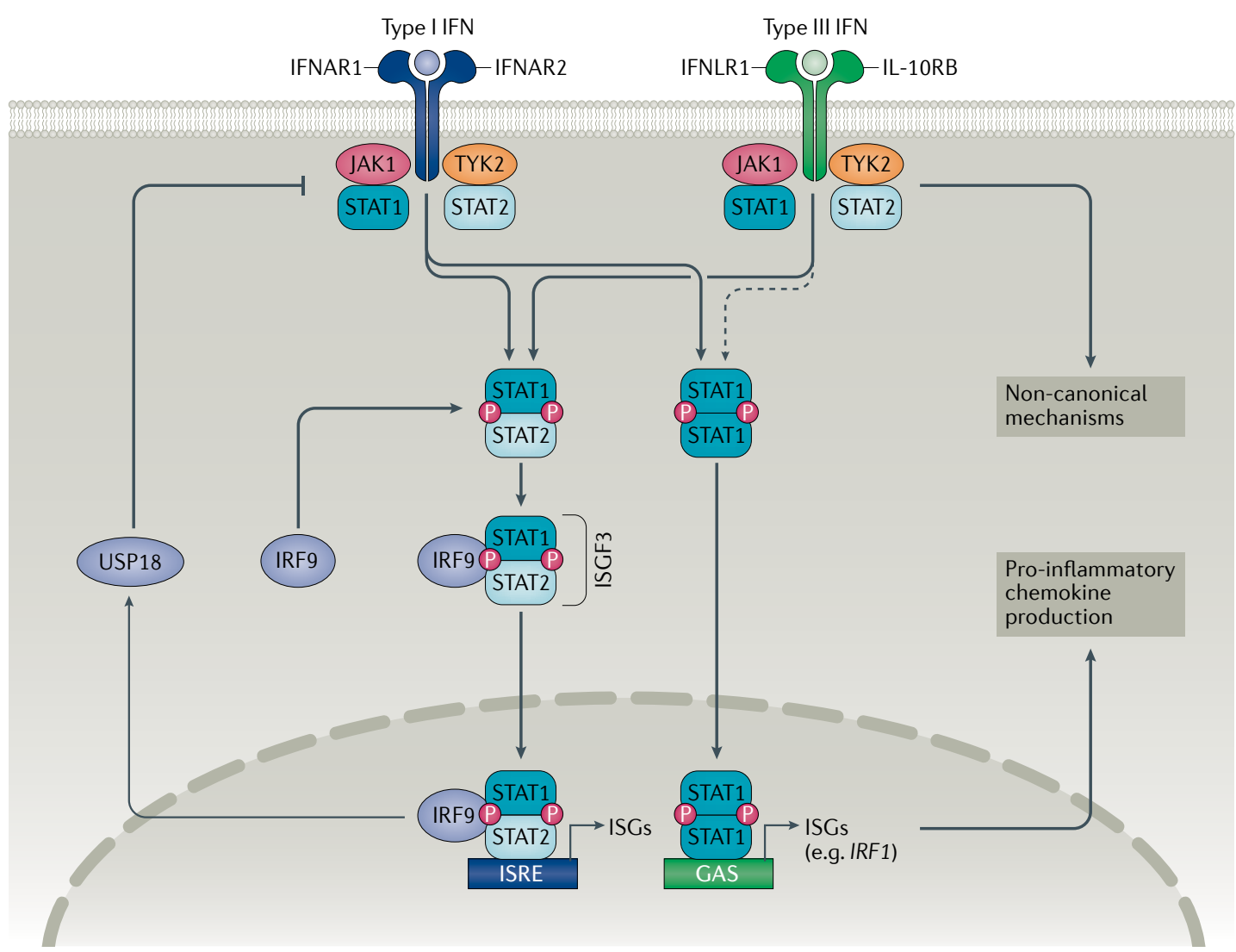

Fig. 1 | Type I and type III interferon signalling pathways. Type I and type III interferons can activate both Janus kinase 1 (JAK1) and non-receptor tyrosine-protein kinase TYK2 (TYK2), leading to signal transducer and activator of transcription (STAT) phosphorylation and the formation of STAT1-STAT2 heterodimers. These heterodimers can interact with interferon regulatory factor 9 (IRF9) to form the interferon stimulated gene factor 3 (ISGF3) transcription factor complex. ISGF3 translocates to the nucleus, where it can bind to interferon-stimulated regulatory element (ISRE) sequences and promote the expression of interferon-stimulated genes (ISGs). Type III interferons comparatively induce lower amplitude expression of ISGs over a longer period of time than type I interferons, possibly owing to differential negative regulation by Ubl carboxylterminal hydrolase 18 (USP18). Type I and type III interferons can also promote the formation of STAT1 homodimers, which upregulate IRF1 expression and lead to pro-inflammatory chemokine production. IFN $\lambda$ can also signal through a variety of non-canonical mechanisms. GAS, IFN $\gamma$-activated sequence; IFN, interferon; IFNAR, IFNa receptor; IFNLR1, IFN $\lambda$ receptor 1; IL-10RB, IL-10 receptor subunit- $\beta$.

regulate antifungal immunity through specific effects on neutrophil function. By contrast, IFN $\lambda$ s can inhibit ROS production and degranulation in mouse neutrophils during intestinal inflammation through a nontranslational, STAT1-independent pathway ${ }^{28}$. Whether human neutrophils are similarly responsive to IFN $\lambda s$ is unclear. Human neutrophils express IFNLR1 and upregulate it in response to inflammatory stimuli such as lipopolysaccharide or fungal infection ${ }^{33}$. IFN $\lambda$ s can also inhibit TNF-induced ROS production in human neutrophils ${ }^{28}$ and suppress neutrophil extracellular trap (NET) formation in response to activated platelets or platelet-derived inorganic polyphosphate ${ }^{34}$. These data are somewhat contradicted by reports that IFN $\lambda$ s do not induce ISG expression in human peripheral blood neutrophils ${ }^{35,36}$, leading to uncertainty about whether and how these cells respond to IFN $\lambda$ s in different settings.

Dendritic cell (DC) subsets are also an important part of the IFN $\lambda$ response network. IFN $\lambda$ s can increase type I interferon and chemokine production by human plasmacytoid DCs (pDCs) $)^{37-39}$ and can upregulate the expression of class I and II MHC molecules and co-stimulatory molecules on pDCs, which could promote $\mathrm{T}$ cell activation ${ }^{37,39}$. By contrast, IFN $\lambda$ s seem to induce a more regulatory phenotype in human monocyte-derived DCs, which promote the expansion of $\mathrm{FOXP}^{+}$regulatory $\mathrm{T}$ cells ${ }^{40}$. Other reports suggest that IFN $\lambda$ s are involved in T cell polarization in vitro ${ }^{41}$ and that they can skew $\mathrm{T}$ cells towards a $\mathrm{T}$ helper 1 cell response in a mouse model of allergic asthma through effects on lung DCs ${ }^{41,42}$. Despite the progress made by these studies, the effects of IFN $\lambda$ s on DC function have not been fully characterized, and it is probable that only certain DC subsets respond directly to this cytokine.

In addition, IFN $\lambda$ s can activate human monocytederived macrophages and promote a pro-inflammatory phenotype, leading to chemokine production and the upregulation of pathways related to antigen presentation, co-stimulation, phagocytosis and cytotoxicity ${ }^{43-46}$. By contrast, natural killer cells do not seem to respond to IFN $\lambda$ s directly ${ }^{35,36,43,47,48}$; however, IFN $\lambda$ s can modulate natural killer cell function indirectly through their effects on macrophages ${ }^{43,48,49}$. 
Table 1 | Direct effects of IFN $\lambda$ s on immune cell populations

\begin{tabular}{|c|c|c|c|c|c|c|c|}
\hline Species & Neutrophils & Macrophages & Dendritic cells & NK cells & B cells & T cells & Refs \\
\hline Mouse & $\begin{array}{l}\text { Increased ISG } \\
\text { expression; } \\
\text { ROS production } \\
\text { can increase } \\
\text { or decrease; } \\
\text { decreased } \\
\text { migration and } \\
\text { IL-1 } \beta \text { production }\end{array}$ & $\begin{array}{l}\text { Increased ISG } \\
\text { expression; increased } \\
\text { stimulation of NK cell } \\
\text { proliferation; some } \\
\text { studies report no } \\
\text { effects }\end{array}$ & $\begin{array}{l}\text { Increased stimulation } \\
\text { of T helper } 1 \text { cell } \\
\text { polarization; increased } \\
\text { stimulation of CD } 8^{+} \text {T cell } \\
\text { responses; increased } \\
\text { ISG expression (pDCs } \\
\text { and BMDCs); increased } \\
\text { antigen presentation and } \\
\text { co-stimulatory molecule } \\
\text { expression (BMDCs); some } \\
\text { studies report no effects }\end{array}$ & $\begin{array}{l}\text { No } \\
\text { effects }\end{array}$ & No effects & No effects & $\begin{array}{r}25,28,32,33,35 \\
42,47,49-52,58,150\end{array}$ \\
\hline Human & $\begin{array}{l}\text { Increased IFNLR1 } \\
\text { expression } \\
\text { on activated } \\
\text { neutrophils; } \\
\text { decreased ROS } \\
\text { production; } \\
\text { decreased NET } \\
\text { formation; some } \\
\text { studies report no } \\
\text { effects }\end{array}$ & $\begin{array}{l}\text { Increased ISG } \\
\text { expression; increased } \\
\text { antigen presentation } \\
\text { and co-stimulatory } \\
\text { molecule expression; } \\
\text { increased cytokine and } \\
\text { chemokine production; } \\
\text { increased phagocytosis } \\
\text { and cytotoxicity; } \\
\text { increased activation } \\
\text { of NK cells }\end{array}$ & $\begin{array}{l}\text { Increased ISG expression } \\
\text { (pDCs); increased cytokine } \\
\text { and chemokine expression } \\
\text { (pDCs); increased } \\
\text { antigen presentation and } \\
\text { co-stimulatory molecule } \\
\text { expression (pDCs and } \\
\text { moDCs) increased } \\
\text { migration (moDCs); } \\
\text { increased stimulation } \\
\text { of regulatory T cell } \\
\text { proliferation (moDCs); } \\
\text { some studies report no } \\
\text { effects in moDCs }\end{array}$ & $\begin{array}{l}\text { No } \\
\text { effects }\end{array}$ & $\begin{array}{l}\text { Increased ISG } \\
\text { expression; } \\
\text { increased } \\
\text { TLR7-mediated } \\
\text { antibody } \\
\text { production; } \\
\text { increased } \\
\text { plasmablast } \\
\text { differentiation }\end{array}$ & $\begin{array}{l}\text { Increased ISG } \\
\text { expression } \\
\text { (CD8 }{ }^{+} \text {T cells } \\
\text { and activated } \\
\text { CD4 }{ }^{+} \text {T cells); } \\
\text { increased IFNLR1 } \\
\text { expression } \\
\text { (activated CD4 }{ }^{+} \\
\text {T cells); some } \\
\text { studies report no } \\
\text { effects }\end{array}$ & $\begin{array}{r}28,33-40,43-46 \\
48,53-55,57\end{array}$ \\
\hline
\end{tabular}

BMDC, bone marrow-derived dendritic cell; IFNLR1, IFN $\lambda$ receptor 1; ISG, interferon-stimulated gene; moDC, monocyte-derived dendritic cell; NET, neutrophil extracellular trap; NK, natural killer; pDC, plasmacytoid dendritic cell; ROS, reactive oxygen species; TLR7, Toll-like receptor 7.

Adaptive immunity. IFN $\lambda$ s also have direct effects on some adaptive immune cells (TABLE 1). Although IFN $\lambda$ s do not seem to affect mouse B cells and $\mathrm{T}$ cells $\mathrm{s}^{35,50-52}$, data indicate that human lymphocytes can respond to IFN $\lambda$ s. The reasons behind the discrepancies between mouse and human responses remain unclear. Human B cells express IFNLR, and stimulation with IFN $\lambda s$ promotes ISG expression in these cells $s^{35,36,53}$. Moreover, IFN $\lambda$ s increase Toll-like receptor 7 (TLR7)-mediated and TLR8-mediated antibody production and plasmablast differentiation in human B cells ${ }^{54,55}$. Pre-treatment with IFN $\lambda$ s can also inhibit influenza-induced IgG production in human peripheral blood mononuclear cells $(\mathrm{PBMCs})^{56}$. However, it is worth noting that this inhibitory effect was observed in a mixed cell population and might result from decreased production of $\mathrm{T}$ helper 2 cell cytokines rather than from a direct effect on $B$ cell function. This idea is consistent with other reports that IFN $\lambda$ s promote $\mathrm{T}$ helper 1 cell skewing via effects on $\mathrm{DCs}^{41,42}$.

The effects of IFN $\lambda$ s on human T cells are less obvious than the effects on B cells. Several reports indicate that human T cells do not express IFNLR1 and are not responsive to IFN $\lambda$ stimulation ${ }^{35,53,57}$. By contrast, a 2020 study has indicated that $\mathrm{CD}^{+} \mathrm{T}$ cells can respond to IFN $\lambda s$ and upregulate ISGs ${ }^{36}$. Activation of T cells with anti-CD3 and anti-CD28 antibodies also upregulated IFNLR1 on $\mathrm{CD} 4^{+} \mathrm{T}$ cells, allowing the induction of ISGs by IFN $\lambda s^{36}$. Therefore, T cells could potentially acquire responsiveness to IFN $\lambda$ s in the context of antigen-specific immune responses.

In addition to direct effects, IFN $\lambda$ s also coordinate adaptive immunity through indirect mechanisms. Ifnlr $1^{-1-}$ mice have decreased antibody and $\mathrm{CD}^{+} \mathrm{T}$ cell responses following infection with influenza virus ${ }^{51}$.
This effect is dependent on thymic stromal lymphopoietin (TSLP) production by microfold cells in the upper airway. IFN $\lambda$ s induce TSLP production in these cells, leading to $\mathrm{CD} 103^{+} \mathrm{DC}$ migration to the draining lymph nodes. These $\mathrm{CD} 103^{+} \mathrm{DCs}$ subsequently promote follicular helper $\mathrm{T}$ cell expansion and germinal centre responses in the lymph node, thereby generating a robust adaptive immune response. Whether this IFN $\lambda$-induced TSLP-mediated mechanism is specific to the respiratory tract and is also present in humans, or whether it can boost adaptive immune responses against self-antigens, remains unclear. A separate study further demonstrated that IFN $\lambda$ s are required for APC migration to the draining lymph nodes and are critical for the development of effective antiviral $\mathrm{CD}^{+} \mathrm{T}$ cell responses during influenza infection in mice ${ }^{58}$, highlighting another mechanism through which IFN $\lambda$ s can potentiate adaptive immune responses.

In summary, these data suggest that IFN $\lambda$ s can modulate immune responses through a variety of direct and indirect pathways. Although these mechanisms have primarily been identified and studied in response to infection, they might also be relevant for autoimmunity. Considerable differences in the IFN $\lambda$ response also exist between mouse and human cells. These differences will be important to consider when evaluating IFN $\lambda$ s in the context of human diseases.

\section{IFN $\lambda$ s in autoimmune rheumatic diseases}

Concentrations of IFN $\lambda$ s are increased in blood and affected tissues in a number of autoimmune rheumatic diseases, including SLE, rheumatoid arthritis (RA), primary Sjögren syndrome (pSS) and systemic sclerosis (SSc). Increased amounts of IFN $\lambda$ s are also associated with increased disease severity, increased 
autoantibodies, increased inflammatory markers and/or specific manifestations in these diseases (TABLE 2). In this section, we summarize the main findings in these diseases and discuss potential mechanisms of immune dysregulation.

Systemic and cutaneous lupus erythematosus. SLE is a complex autoimmune disease that can affect multiple organ systems, including the skin, kidneys, joints and vasculature. The role of type I interferons is well established in SLE pathogenesis, and many patients with SLE display a characteristic type I interferon signature in blood and affected tissues ${ }^{59-61}$. Functionally, type I interferons lead to the aberrant activation of immune cells $s^{62}$ by promoting autoantibody production and immune complex formation that result in tissue damage. Type I interferons can also prime neutrophils, modify APC activity and regulate $\mathrm{T}$ cell function to further promote autoimmune tissue damage in SLE.

In addition to type I interferons, evidence suggests that type III interferons are dysregulated in SLE. Several studies have reported that serum IFN $\lambda 1$ and IFN $\lambda 3$ concentrations are increased in patients with SLE compared with healthy individuals ${ }^{63-71}$. IFNL1 transcripts are increased in PBMCs and IFNL2 and IFNL3 transcripts are increased in activated $\mathrm{CD} 4^{+} \mathrm{T}$ cells from patients with SLE relative to those from healthy individuals ${ }^{63,72}$. Moreover, increased serum concentrations of IFN $\lambda \mathrm{s}$ are associated with disease severity and clinical laboratory values. Specifically, higher serum concentrations of IFN $\lambda$ correlate with higher SLE Disease Activity Index scores ${ }^{63-66}$, higher anti-double-stranded DNA (dsDNA) autoantibody titres ${ }^{63,64}$ and lower amounts of complement proteins C3 and C4 (REFS ${ }^{63-66}$ ). Increased circulating concentrations of IFN $\lambda$ s are also associated with the presence of specific disease manifestations in SLE, including arthritis, nephritis, serositis and skin involvement ${ }^{63,65,71}$. Genetic studies further implicate IFN $\lambda$ s in SLE pathogenesis. IFNL3 and IFNL4 variants are risk factors for lupus nephritis among patients with
SLE in a Taiwanese cohort $^{66}$, and the rs4649203 single nucleotide polymorphism in IFNLR1 is associated with an increased risk of SLE in a Chinese Han population ${ }^{73}$.

IFN $\lambda$ s have also been detected in affected tissues in patients with SLE. Immunohistochemistry analysis of skin tissue showed that IFN $\lambda$ s and IFNLR1 are substantially increased in patients with chronic discoid lupus erythematosus or subacute cutaneous lupus erythematosus (CLE) relative to healthy individuals or patients with other inflammatory skin diseases (such as atopic dermatitis or psoriasis) ${ }^{69}$. The detection of IFN $\lambda$ s in the skin of patients with CLE is most prominent in the epidermis, with some additional staining of mononuclear cells in the dermis. Patients with CLE also have increased serum IFN $\lambda 1$ concentrations, particularly in those patients with disseminated lesions compared with those with more localized disease, and a case report from a single patient found that serum IFN $\lambda 1$ concentrations declined during clinical remission following treatment with glucocorticoids and hydroxychloroquine ${ }^{69}$. In addition to skin, IFN $\lambda$ s and IFNLR1 are also detectable in kidney tissue from patients with lupus nephritis $^{66,70}$; IFN $\lambda$ s were mostly observed in glomerular crescents and areas with inflammatory infiltrates, and glomerular IFN $\lambda$ staining decreased in repeat biopsyretrieved samples from patients who achieved a histological response to treatment ${ }^{70}$. However, these studies did not include kidney tissue samples from healthy individuals or disease-matched controls. Overall, these findings indicate that IFN $\lambda$ s might be involved in SLE-associated skin and kidney disease.

Data from mouse models support a mechanistic role for IFN $\lambda s$ in SLE. One study investigated the effects of IFN $\lambda$ s in a TLR7-induced lupus model, whereby mice are repeatedly exposed to the TLR7 agonist imiquimod. Serum concentrations of IFN $\lambda 2$ and IFN $\lambda 3$ were increased in imiquimod-treated mice, and IFNLR1 deficiency substantially reduced splenomegaly and leucocytosis compared with wild-type controls ${ }^{35}$. Ifnlr $1^{-/}$mice were fully responsive to IFNa, suggesting that IFN $\lambda$ s

Table 2 | IFN $\lambda$ s in autoimmune rheumatic diseases

\begin{tabular}{|c|c|c|c|c|c|c|c|}
\hline Disease & $\begin{array}{l}\text { Expression } \\
\text { in blood }\end{array}$ & $\begin{array}{l}\text { Expression } \\
\text { in tissue }\end{array}$ & Disease activity & Antibodies & $\begin{array}{l}\text { Inflammatory } \\
\text { markers }\end{array}$ & $\begin{array}{l}\text { Associated disease } \\
\text { manifestations }\end{array}$ & Refs \\
\hline SLE & $\begin{array}{l}\text { Increased IFN } \lambda 1 \\
\text { and IFN } \lambda 3 \text {; } \\
\text { increased IFNL1 } \\
\text { mRNA (PBMCs); } \\
\text { increased IFNL2 } \\
\text { and INFL3 mRNA } \\
\text { (CD4+ T cells) }\end{array}$ & $\begin{array}{l}\text { Increased } \\
\text { IFN } \lambda \text { s in skin } \\
\text { and kidneys }\end{array}$ & $\begin{array}{l}\text { Not associated } \\
\text { with SLAM; } \\
\text { contradictory } \\
\text { results for } \\
\text { SLEDAI and SDI }\end{array}$ & $\begin{array}{l}\text { Associated with } \\
\text { anti-nucleosome } \\
\text { antibodies; not } \\
\text { associated with } \\
\text { ANAs; contradictory } \\
\text { results for anti-dsDNA } \\
\text { antibodies }\end{array}$ & $\begin{array}{l}\text { Associated with } \\
\text { a decrease in } \\
\text { complement } \\
\text { proteins C } 3 \text { and C4; } \\
\text { not associated with } \\
\text { ESR; contradictory } \\
\text { results for CRP }\end{array}$ & $\begin{array}{l}\text { Arthritis, nephritis, } \\
\text { serositis and skin } \\
\text { involvement }\end{array}$ & $63-72$ \\
\hline $\begin{array}{l}\text { Primary } \\
\text { Sjögren } \\
\text { syndrome }\end{array}$ & Increased IFN $\lambda 1$ & $\begin{array}{l}\text { Increased } \\
\text { IFN } \lambda 1 \text { in minor } \\
\text { salivary glands }\end{array}$ & ND & ND & ND & $\begin{array}{l}\text { Exocrine gland } \\
\text { involvement }\end{array}$ & 94,95 \\
\hline
\end{tabular}


have important and non-redundant functions in systemic immune dysregulation. Further investigation of splenic immune cell populations revealed that IFN $\lambda s$ promote myeloid cell expansion and $\mathrm{T}$ cell activation following in vivo TLR7 stimulation, potentially through a combination of direct and indirect effects on these cells. By contrast, IFN $\lambda$ s did not modulate B cell responses in TLR7-induced lupus, as the number of plasma cells and levels of B cell activation markers did not differ between Ifnlr $1^{-/-}$mice treated with imiquimod and wild-type controls. IFNLR1 deficiency also had no effect on the amounts of circulating antinuclear antibodies or anti-dsDNA autoantibodies. These results ${ }^{35}$ are somewhat contradictory to data in humans, which indicate that increased concentrations of IFN $\lambda$ s correlate with

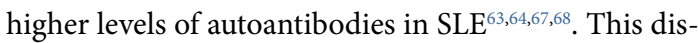
crepancy could potentially be related to differences in $B$ cell responsiveness to IFN $\lambda$ s between mice and humans. Mouse B cells are unresponsive to IFN $\lambda$ s, whereas human B cells can respond directly to this cytokine by increasing TLR7-mediated antibody production and plasmablast differentiation ${ }^{54,55}$. Therefore, additional research is needed to determine how IFN $\lambda$ affects autoantibody production in the context of human SLE.

Mouse models of lupus also support a role for IFN $\lambda s$ in the pathogenesis of skin and kidney manifestations in SLE. If $n l r 1^{-1-}$ mice had substantially reduced skin inflammation in the TLR7-induced lupus model ${ }^{35}$. This decrease in skin inflammation corresponded with a decrease in tissue expression of pro-inflammatory genes such as $\mathrm{Il6}, \mathrm{Cxcl} 9$ and $\mathrm{Cxcl} 10$. In vitro experiments show that mouse and human keratinocytes respond to IFN $\lambda \mathrm{s}$ and can upregulate CXCL9, CXCL10 and CXCL11 chemokines $^{35}$. Moreover, culture supernatants from IFN $\lambda$-stimulated human keratinocytes can induce the in vitro migration of mononuclear immune cells ${ }^{35,69}$. These data suggest that IFN $\lambda$ s might, at least in part, promote SLE-associated skin disease by increasing pro-inflammatory chemokine production in keratinocytes (FIG. 2). Notably, co-treatment of keratinocytes with IFN $\alpha$ and IFN $\lambda 1$ induced greater chemokine expression than either cytokine alone ${ }^{35}$, indicating that type I and type III interferons could have an additive effect in promoting skin inflammation. IFN $\lambda$ s also increase the expression of MHC class I molecules by human keratinocytes, which can in turn promote pathogenic $\mathrm{CD}^{+} \mathrm{T}$ cell responses ${ }^{74}$. In the same TLR7-induced lupus model, Ifnlr $1^{-1-}$ mice also had decreased immune complex deposition, glomerulosclerosis and ISG expression in the kidneys ${ }^{35}$. IFN $\lambda$ s were able to induce ISGs and chemokine production in mouse mesangial cells, suggesting that IFN $\lambda$ s could have an important effect on structural cells in the kidney. Other kidney cells, in particular those of epithelial origin, can also potentially respond to IFN $\lambda s^{75}$. Further analysis is required to identify and characterize how IFN $\lambda$ s can affect other tissues, such as the lung, brain and joints, that are commonly involved in SLE; however, unlike type I interferons, type III interferons do not seem to have any effects on vascular disease in mice, as IFNLR1 deficiency did not improve endothelium-dependent vasorelaxation in the TLR7-induced lupus model ${ }^{35}$.
Interferon production in SLE occurs through a variety of mechanisms involving nucleic acids, immune complexes and the engagement of various intracellular sensors (FIG. 2). pDCs are a major source of type I interferons in $\mathrm{SLE}^{76}$ and are also involved in IFN $\lambda$ production. These cells accumulate in the skin of mice with lupus and produce IFN $\lambda$ s in response to TLR7 agonists ${ }^{35}$. In humans, RNA-containing immune complexes can induce the production of type III interferons in a subset of pDCs that also produce type I interferons ${ }^{77}$. The production of IFN $\lambda$ s by pDCs in vitro was attenuated in the presence of hydroxychloroquine or an IL-1 receptor associated kinase 4 (IRAK4) inhibitor, indicating that RNA-containing immune complexes induce the production of IFN $\lambda$ s through the endosomal TLRmyeloid differentiation primary response protein (MyD88) system. Additional research is needed to determine whether other immune stimuli that trigger type I interferon production, such as NETs ${ }^{78,79}$, can also contribute to the production of IFN $\lambda$ s in SLE. In addition to $\mathrm{pDCs}$, keratinocytes seem to be a potential source of IFN $\lambda s$ in the skin. Epidermal explants and cultured human keratinocytes produce considerable amounts of IFN $\lambda$ s in response to synthetic TLR3 agonists ${ }^{69}$. A followup study demonstrated that endogenous nucleic acids isolated from keratinocytes, in combination with the cathelicidin LL-37, were able to induce the production of IFN $\lambda s^{80}$. These results are consistent with the finding that keratinocyte cell death and increased amounts of nuclear debris perpetuate inflammation in SLE skin lesions ${ }^{81}$ (FIG. 2). Keratinocytes can also upregulate IFNL transcripts after stimulation with IFNa ${ }^{35}$, highlighting another potential feed-forward pro-inflammatory loop whereby type I interferon amplifies the type III interferon pathway in skin. Overall, current data indicate that IFN $\lambda$ s are potentially pathogenic in SLE, causing cell-specific and tissue-specific effects.

Rheumatoid arthritis. RA is a systemic autoimmune disease that leads to chronic inflammation, cartilage damage and bone erosion in synovial joints. Proinflammatory cytokines such as TNF and IL- 6 are important in the pathogenesis of $\mathrm{RA}^{82}$; however, blocking these cytokines is not effective in all patients with RA, suggesting that additional pathways are involved. Similar to SLE, a subset of patients with RA display a type I interferon signature in blood $^{83}$. pDCs and type I interferons have also been detected in RA synovium ${ }^{84,85}$, further indicating that interferons might contribute to RA immunopathology.

Notably, IFN $\lambda$ s are also upregulated in RA. IFN $\lambda 1$ is substantially increased in serum from patients with RA compared with serum from healthy individuals or patients with ankylosing spondylitis ${ }^{86-89}$. IFNL1 transcripts are also increased in PBMCs from patients with $\mathrm{RA}$ and, in addition, IFN $\lambda 1$ is increased in synovial fluid from patients with RA compared with synovial fluid from patients with osteoarthritis ${ }^{88}$. Despite there being increased amounts of IFN $\lambda$ s in blood and synovial fluid in RA, data on associations between IFN $\lambda$ s and clinical features in RA are mixed. Several studies have reported no correlations between serum IFN $\lambda 1$ 


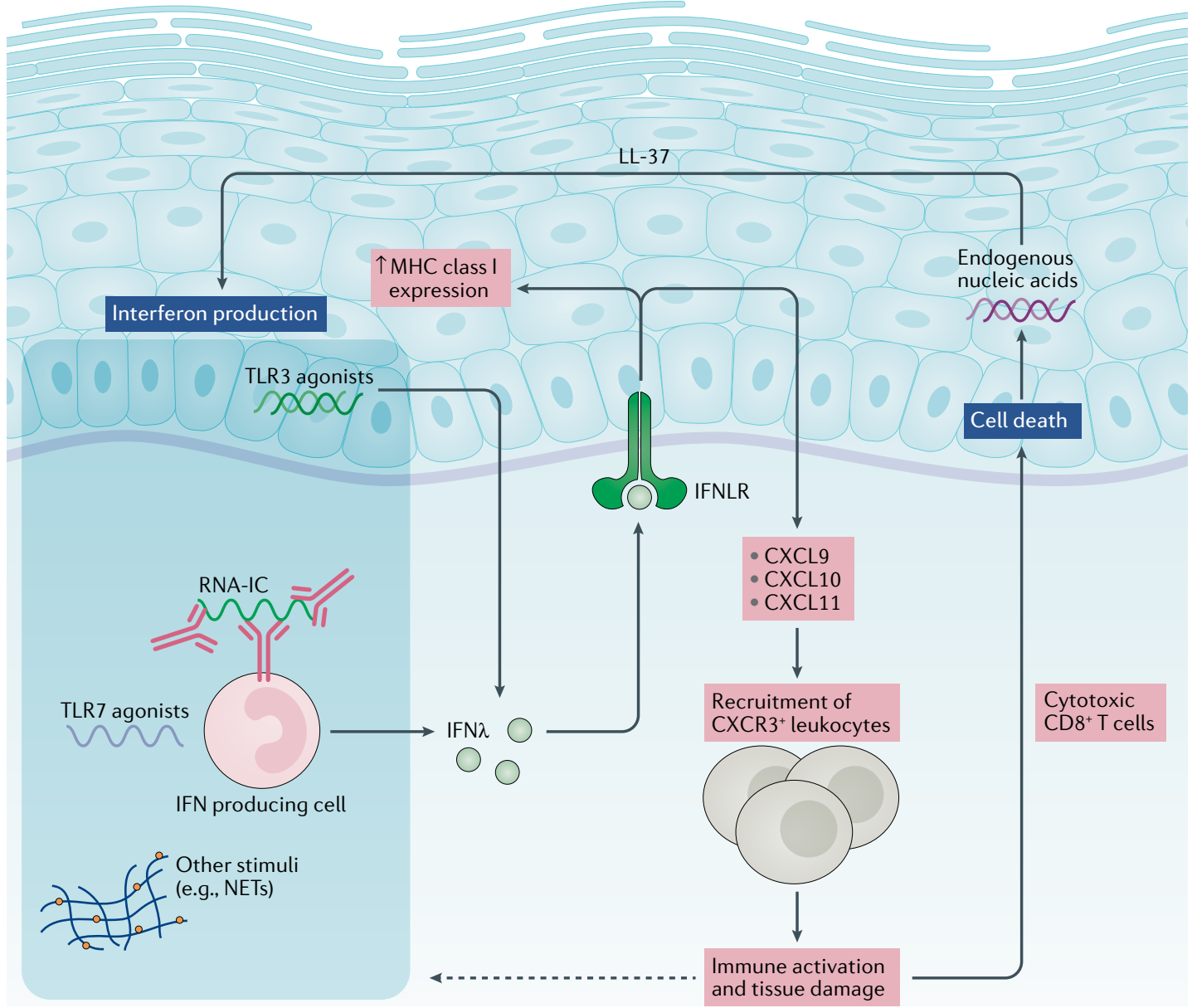

Fig. 2 | IFN $\lambda$ s in skin disease in systemic lupus erythematosus. Danger signals, including Toll-like receptor 7 (TLR7) agonists and RNA-containing immune complexes (RNA-IC), can induce the production of IFN $\lambda$ s by plasmacytoid dendritic cells. TLR3 agonists can also induce the production of IFN $\lambda$ s by keratinocytes. IFN $\lambda$ s can subsequently activate keratinocytes to upregulate the expression of the chemokines CXCL9, CXCL10 and CXCL11, as well as surface MHC class I molecules. These chemokines recruit $\mathrm{CXCR} 3^{+}$leukocytes to the skin, where they promote tissue damage; in particular, cytotoxic $C D 8^{+} T$ cells can cause keratinocyte cell death. The release of endogenous nucleic acids (in combination with the cathelicidin LL-37 in experimental models) can induce further production of IFN $\lambda$ s, resulting in a feed-forward loop that perpetuates inflammation in the skin. Whether inflammatory stimuli can also upregulate IFN $\lambda$ receptor (IFNLR) expression on keratinocytes is unclear. NET, neutrophil extracellular trap.

concentrations and clinical parameters, including the 28-joint Disease Activity Score (DAS28), circulating inflammatory markers (such as C-reactive protein) or RA-associated autoantibodies (rheumatoid factor and anti-citrullinated protein antibodies) ${ }^{86,88}$. Although IFN $\lambda 1$ was not associated with the presence of autoantibodies, it was associated with knee joint involvement ${ }^{86}$. By contrast, a separate study reported that serum IFN $\lambda 1$ concentrations correlated with the presence of RA-associated autoantibodies, and also correlated with worse DAS28 scores in patients positive for anti-citrullinated protein antibodies ${ }^{89}$. Moreover, IFN $\lambda 1$ concentrations decrease following 6 months of treatment with DMARDs ${ }^{89}$. IFN $\lambda 1$ concentrations have also been associated with the presence of anti-mutated citrullinated vimentin autoantibodies, and IFN $\lambda 2$ concentrations are only increased in patients with active RA (defined by a DAS28 score of $>2.6$ ) $^{87}$, suggesting that each IFN $\lambda$ might contribute to specific disease processes. Further assessment of whether this cytokine modulates human B cell function and autoantibody production in RA will be important.

In the synovium, IFN $\lambda 1$ co-localizes with $\mathrm{CD} 8^{+}$ cells and FGF2 ${ }^{+}$cells ${ }^{88}$, suggesting that macrophages and synovial fibroblasts might be relevant sources of IFN $\lambda$ s in RA. In vitro experiments also indicate that synovial fibroblasts can respond to IFN $\lambda$ s. A human RA synovial fibroblast cell line expresses IFNLR1, and stimulation of these cells with recombinant IFN $\lambda 1$ upregulates $I L 6$, IL8 and MMP3 expression ${ }^{88}$. IFN $\lambda$ s also upregulate the expression of TLRs 2, 3 and 4 in the same synovial fibroblast cell line, thereby amplifying TLR-mediated IL-6 and IL-8 production ${ }^{90}$. These results suggest that IFN $\lambda$ s might promote joint inflammation and damage in RA.

Other data indicate that IFN $\lambda$ s actually have the opposite effect and are protective against inflammatory arthritis. In one study, treatment with recombinant IFN $\lambda 2$ suppressed neutrophil infiltration and IL- $1 \beta$ production in mice with collagen-induced arthritis ${ }^{32}$. Another study showed that IFN $\lambda 1$ can inhibit osteoclast 
formation in vitro ${ }^{91}$, suggesting that IFN $\lambda 1$ might be protective against bone erosion in RA. Overall, it is still unclear if IFN $\lambda$ s are pathogenic in RA, and further research is needed to better characterize how IFN $\lambda$ s could contribute to immune dysregulation and joint damage in this disease. Notably, variability in responses to type III interferons by human and mouse cells could complicate interpretation of data in the context of animal models of RA in future studies.

Other autoimmune rheumatic diseases. pSS is a systemic autoimmune condition that targets exocrine glands, resulting in a dry mouth, dry eyes and several systemic manifestations. pSS is characterized by an exaggerated type I interferon response in blood and affected glands ${ }^{92,93}$, and evidence indicates that IFN $\lambda s$ might also contribute to the immunopathology of pSS. Immunohistochemistry analysis of minor salivary glands has demonstrated that expression of IFN $\lambda s$ is increased in tissue from patients with pSS compared with tissue from individuals with non-pSS sicca symptoms ${ }^{94,95}$. Serum IFN $\lambda 1$ concentrations are similarly increased in patients with $\mathrm{pSS}^{94}$.

Salivary gland epithelial cells might contribute to both the production of IFN $\lambda$ s and the IFN $\lambda$ response in pSS. TLR 3 agonists induce the production of IFN $\lambda$ s by salivary gland epithelial cells, which in turn upregulates CXCL10 and BAFF (which encodes B cell activating factor (BAFF)) expression in these cells ${ }^{94,95}$. Co-treatment with IFN $\alpha$ and IFN $\lambda 1$ can further enhance STAT 1 phosphorylation and cytokine expression in salivary gland epithelial cells, suggesting that type I and type III interferons could have combined effects in pSS. BAFF is a known pathogenic factor in pSS and promotes $\mathrm{B}$ cell hyperactivity and autoantibody production ${ }^{92}$. On the basis of these findings, it will be important to further investigate the potential link between IFN $\lambda$ s and aberrant $B$ cell responses in pSS.

IFN $\lambda$ s also have potential effects in SSc, an autoimmune disease characterized by vasculopathy and widespread fibrosis in the skin, lungs and other organs. The amount of IFN $\lambda 1$ is increased in the serum of patients with SSc (both diffuse and limited cutaneous subtypes) compared with healthy controls ${ }^{96}$. Concentrations of IFN $\lambda s$ are highest in patients with SSc who have muscle involvement and correlate positively with concentrations of IFN $\gamma$, suggesting that IFN $\lambda$ s might interact with other cytokine networks to amplify pathogenicity in SSc. Notably, the rs 12979860 variant of IFNL3 is associated with an increased risk of pulmonary fibrosis in $\mathrm{SSc}^{97}$, whereas no associations have been reported between this variant and skin fibrosis. Serum IFN $\lambda 3$ concentrations are also higher in patients with SSc who have pulmonary fibrosis than in those patients with SSc who do not develop this complication, and Ifnl3 transcripts are increased in lung tissue in a mouse model of pulmonary fibrosis ${ }^{97}$. However, additional research is needed to identify the cellular targets and pathways responsible for the pro-fibrotic effects of IFN $\lambda$ s in SSc.

Preliminary evidence also exists suggesting that IFN $\lambda$ expression is dysregulated in other autoimmune and inflammatory diseases. The expression of
IFN $\lambda s$ is increased in skin samples from patients with dermatomyositis ${ }^{69}$. By contrast, expression of IFN $\lambda 1$ is decreased in the ocular fluid of patients with juvenile idiopathic arthritis-associated uveitis ${ }^{98}$. No further investigation has been carried out into how IFN $\lambda$ s might relate to pathogenesis, disease severity or other immunological parameters in these diseases. IFN $\lambda$ s have also been implicated in psoriasis and inflammatory bowel disease ${ }^{99,100}$, which are beyond the scope of this Review, and it remains unclear if IFN $\lambda$ s are involved in seronegative spondyloarthritis, which is associated with these conditions.

\section{Are IFN $\lambda$ s protective or harmful?}

IFN $\lambda$ s seem to have considerable pro-inflammatory and anti-inflammatory effects that are highly context dependent. As discussed in previous sections, concentrations of IFN $\lambda$ s are increased and could have pathogenic effects in autoimmune diseases such as SLE. Data obtained during the COVID-19 pandemic also indicate that persistent IFN $\lambda$ signalling can disrupt epithelial barrier function in the lungs and predispose individuals to bacterial superinfection ${ }^{101,102}$, further highlighting the possibility of IFN $\lambda$-mediated tissue damage. By contrast, compelling data suggest that IFN $\lambda$ s can be protective against inflammation by regulating neutrophil function in mouse models of arthritis, colitis and thromboinflammation ${ }^{28,32,34}$, as well as promoting mucosal healing in the gastrointestinal tract ${ }^{100}$.

One explanation for these seemingly contradictory effects of IFN $\lambda s$ is the expression level of IFNLR. As discussed in a previous section, IFNLR density on epithelial cells seems to regulate the pro-inflammatory effects of IFN $\lambda$ s. Specifically, cells expressing high amounts of IFNLR1 are able to induce sufficient IRF1 expression to produce pro-inflammatory chemokines such as CXCL10 (REF. ${ }^{27}$ ). Therefore, it is possible that local or systemic inflammatory processes in SLE and other autoimmune rheumatic diseases can increase IFNLR1 expression above the threshold necessary for IRF1 induction. For example, IFNLR1 staining is increased in the epidermis of patients with CLE ${ }^{69}$, and Ifnlr1 expression is substantially upregulated in the skin of mice with TLR7-induced lupus compared with healthy controls ${ }^{35}$ (FIG. 2). Data from primary human hepatocytes suggest that IFNa can upregulate IFNLR1 expression and that this effect is dependent on the IFNL3 genotype of the cells ${ }^{103}$. Such interactions between type I and type III interferons could also be important in autoimmune rheumatic diseases such as SLE. Additional research is needed to better understand how IFNLR is expressed and regulated in autoimmunity.

Another possibility is that there are cell-specific and tissue-specific differences in IFNLR1 expression, both during homeostasis and in the context of inflammatory pathology. These differences might explain why concentrations of IFN $\lambda$ s correlate with clinical phenotypes in some tissues (such as the skin and kidneys), but not in others. At present, limited data exist on how individual cell types in a tissue respond to IFN $\lambda$ s. Single-cell and spatial transcriptomic analyses will enable better characterization of type III interferon responses in various tissues. 
Such approaches will help investigators to identify IFN $\lambda$-responsive cell types from bulk samples, rather than having to sort individual cell types or use genetically engineered models. Similarly, single-cell approaches will also help researchers to investigate the levels of sensitivity and/or distinct patterns of transcriptional responses to IFN $\lambda s$ in individual cell types or in cells at different stages of differentiation. For example, human neutrophils might gain responsiveness to IFN $\lambda$ s under certain conditions, such as fungal infection ${ }^{33}$. Although no differences were detected in IFN $\lambda$ responses between neutrophils from patients with SLE and those from healthy individuals in peripheral blood ${ }^{35}$, it will be necessary to study leukocyte responses in situ, as these cells could be regulated by local environmental factors in inflamed tissues.

Additionally, IFN $\lambda$ subtypes could potentially have different immunoregulatory functions. Concentrations of IFN $\lambda s$ 1-3 are all increased in patients with autoimmune rheumatic diseases (TABLE 2); however, mechanistic studies have largely focused on genetic deletion of Ifnlr 1 , which abrogates signalling by all IFN $\lambda$ subtypes. Although there are currently insufficient data to define mechanisms for potential differences between IFN $\lambda$ subtypes, one possible explanation is their different affinities for IFNLR ${ }^{104}$. Specifically, IFN $\lambda 1$ seems to bind to IFNLR with the highest affinity of the IFN $\lambda$ subtypes, which could generate differences in signalling output, leading to distinct biological potencies of IFN $\lambda s^{105,106}$. Differential kinetics and magnitudes of IFN $\lambda$ subtype induction, different stability, bioavailability and tissue distribution of the proteins, and different sensitivity to negative regulators might also result in distinct activities of IFN $\lambda$ subtypes.

More broadly, IFN $\lambda$ s could have additional roles in immune homeostasis via effects on central tolerance and $\mathrm{T}$ cell education in the thymus ${ }^{107}$. IFN $\lambda$ s are constitutively expressed in medullary thymic epithelial cells and promote MHC class I molecule expression in thymic epithelial cells. IFN $\lambda$-induced MHC class I expression seems to be crucial for effective $\mathrm{T}$ cell selection, as Ifnlr $1^{-/-}$mice have impaired negative selection of $\mathrm{T}$ cells ${ }^{107}$. Functionally, this lack of negative selection results in Ifnlr $1^{-/-}$mice developing spontaneous autoimmune manifestations such as immune cell infiltration in the lung and kidneys. Ifnlr $1^{-/-}$mice also have increased amounts of total IgG antibodies and develop some tissue-reactive autoantibodies ${ }^{107}$. Together, these data indicate that IFN $\lambda$ s have myriad effects in different health and disease states.

\section{Implications for treatment}

Interferons are important factors underlying the immunopathogenesis of autoimmune rheumatic diseases. Accordingly, the interferon pathway has been an attractive therapeutic target, and several drug candidates (both interferons themselves and interferon-inhibiting therapies) are currently under investigation for SLE and other diseases. Pegylated-IFN $\lambda$ has been studied as a novel treatment for viral hepatitis and is being tested for COVID-19 (REFS ${ }^{108-110}$ ). Data from mouse models also show that recombinant IFN $\lambda 1$ suppresses joint inflammation in mice with collagen-induced arthritis by inhibiting neutrophil recruitment ${ }^{32}$. Accordingly, IFN $\lambda 1$ has been proposed as a potential treatment for controlling neutrophil-mediated pathology in rheumatic diseases. However, it is still unclear if IFN $\lambda 1$ has similar effects on human neutrophils to its effects on mouse neutrophils, and it is important to consider off-target effects of IFN $\lambda$ s that might actually worsen autoimmune disease.

The interferon-inhibiting therapies can be categorized into three main groups: drugs that target interferons (both the cytokine and the receptor); drugs that inhibit downstream JAK-STAT signalling; and drugs that inhibit interferon production. Current therapies that target interferons and their receptors only block the type I interferon pathway, whereas therapies that target JAK-STAT signalling components or interferon production can block the effects of both type I and type III interferons (FIG. 3, TABLE 3).

Targeting interferons. Several neutralizing antibodies that recognize IFNa, including sifalimumab and rontalizumab, have been tested in clinical trials for SLE. A phase II trial of sifalimumab met its primary end point for efficacy of an SLE Responder Index (SRI) response in patients with moderate-to-severe active SLE ${ }^{111}$. In addition to producing an SRI response, sifalimumab was moderately effective at reducing tissue-specific disease activity in the skin and joints. By contrast, a phase II trial of rontalizumab failed to meet its primary and secondary end points for reducing disease activity in patients with SLE $^{112}$. The development programmes for both sifalimumab and rontalizumab have since been discontinued, and these therapies are no longer being developed for $\mathrm{SLE}^{113}$. Sifalimumab was also tested in a phase I trial for dermatomyositis and polymyositis, in which it suppressed the interferon gene signature in blood and had some effects in muscle tissue ${ }^{114,115}$.

An alternative method for blocking IFNa using IFNa kinoid (IFN-K) has also been tested in phase II clinical trials in SLE. In this approach, inactivated IFNa is conjugated to a carrier protein and combined with an adjuvant to induce the production of endogenous anti-IFNa antibodies. Notably, this vaccine-like preparation induces polyclonal antibodies that might be more effective at neutralizing all IFNa subtypes than monoclonal antibodies. Immunization with IFN-K significantly reduced the interferon gene score and met secondary end points for clinical efficacy in patients with SLE ${ }^{116-118}$. However, inducing long-term immunity against interferons could increase the risk of infection ${ }^{119}$ and the safety profile of IFN-K merits further study.

Overall, antibodies that target IFNa seem to have had mixed efficacy for rheumatic diseases. Because these antibodies specifically target IFNa, it is possible that other type I interferons (such as IFN $\beta$ or IFNK) are still able to bind to the type I interferon receptor without interruption. Moreover, these antibodies have no effect on type III interferons. Of note, a soluble glycoprotein encoded by Yaba-like disease virus can effectively neutralize all human type I and type III interferons ${ }^{120}$, demonstrating the possibility of developing a 


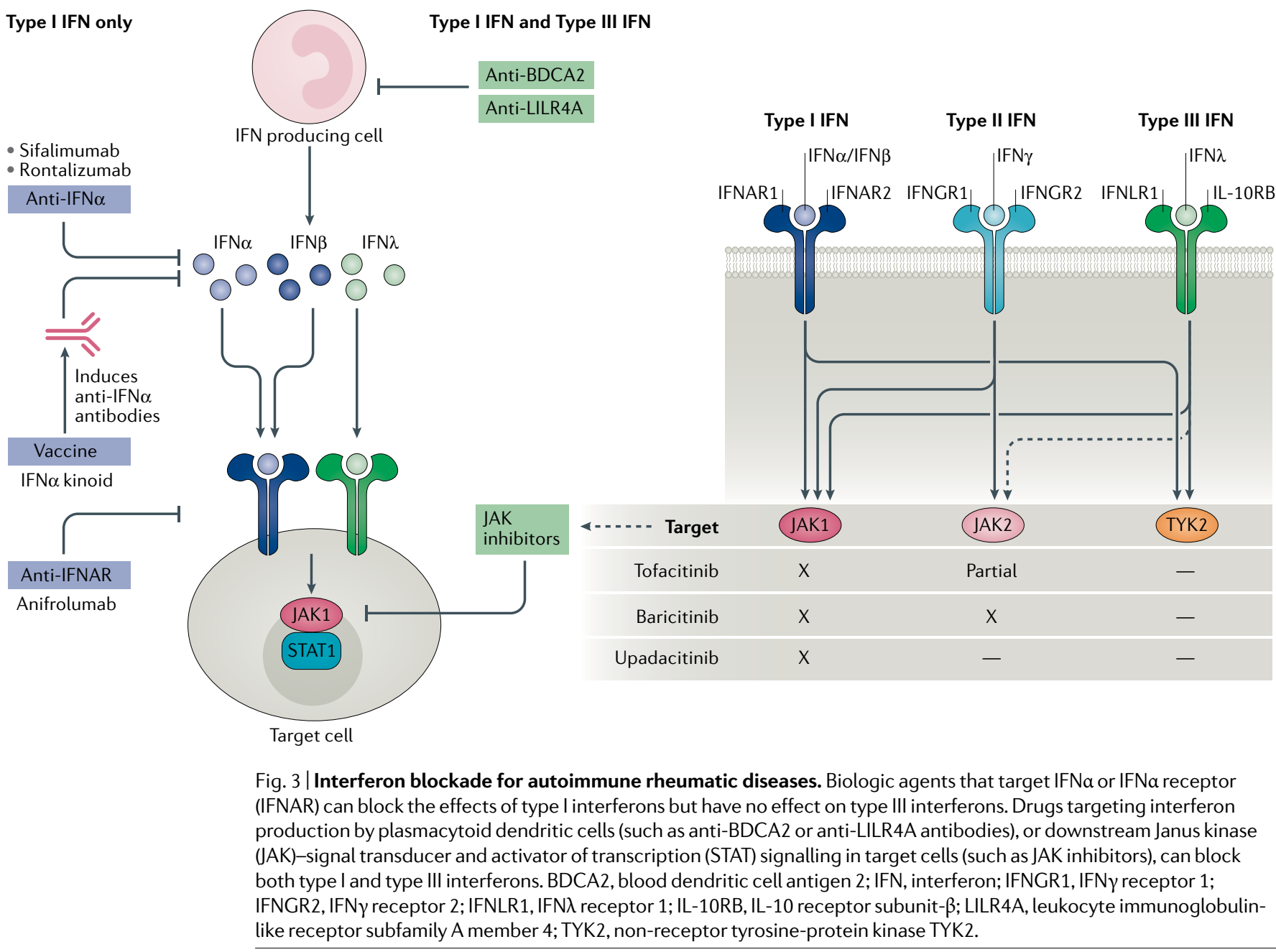

pan-interferon antagonist without also targeting signalling components shared by other cytokines (such as occurs with JAK inhibitors). Further research is needed to evaluate the safety and efficacy of this approach.

Targeting interferon receptors. Anifrolumab, a monoclonal antibody that targets IFNAR, is also being investigated in SLE. Data from phase III trials are encouraging, although results are somewhat conflicting. Anifrolumab failed to meet its primary end point of an SRI response in the TULIP-1 trial ${ }^{121}$. However, anifrolumab significantly reduced disease activity, as measured by a primary BILAG-Based Composite Lupus Assessment response, in the subsequent TULIP-2 trial ${ }^{122}$. Anifrolumab also reduced glucocorticoid use and improved skin disease in TULIP-2. Further analysis from a phase IIb trial showed that anifrolumab could reduce markers of cardiometabolic dysfunction in patients with SLE, suggesting that it might have additional benefit in SLE vasculopathy ${ }^{123}$. Anifrolumab is also being evaluated in a phase II trial for patients with active proliferative lupus nephritis ${ }^{124}$.

In addition to SLE, anifrolumab is also being investigated in other autoimmune rheumatic diseases. Anifrolumab is currently being tested in a phase IIa proof-of-concept trial for patients with moderate-tosevere RA who have an increased interferon gene signature and who have not responded to other biologic DMARDs $^{125}$. Anifrolumab was also tested in a phase I trial for SSc, in which it suppressed the interferon gene signature in whole blood and skin, which corresponded with a decrease in markers associated with $T$ cell activation and collagen accumulation ${ }^{126,127}$. However, although targeting IFNAR should block signalling by all type I interferons, it will have no effect on IFN $\lambda$ signalling. At present, no drugs are available that specifically target IFN $\lambda$ s or their receptor.

Targeting the JAK-STAT signalling pathway. JAK inhibitors are a promising new treatment for SLE that target and block the downstream signalling cascades of multiple cytokines involved in pathogenesis, including both type I and type III interferons. Moreover, these drugs can be given orally as opposed to intravenously like other biologic agents ${ }^{128,129}$. The JAK1 and JAK2 inhibitor baricitinib met its primary end point for clinical efficacy in a phase II trial in SLE, in which a higher proportion of patients receiving baricitinib achieved resolution of rash or arthritis compared with those who received placebo ${ }^{130}$. Phase III trials for baricitinib in SLE are ongoing ${ }^{131-133}$. Tofacitinib, a non-selective JAK1 and JAK3 inhibitor, has also shown potential in pre-clinical lupus models ${ }^{121}$, and in a phase Ib/IIa trial 
for mild-to-moderate SLE it demonstrated a good safety profile and improved cardiometabolic parameters ${ }^{134,135}$.

JAK inhibitors have been extensively studied in RA, and several drugs (tofacitinib, baricitinib and upadacitinib) have been approved for clinical use by the FDA (reviewed elsewhere ${ }^{128,129}$ ). The efficacy of JAK inhibitors is probably related to their simultaneous targeting of multiple effector cytokines; however, there are currently no data on how JAK inhibitors modulate the interferon response in RA. JAK inhibitors are being investigated for pSS, SSc and myositis. Tofacitinib is currently in a phase I/II trial for $\mathrm{pSS}^{136}$, and a phase I/II trial for early diffuse $\mathrm{SSc}^{137}$ was recently completed, in which the drug was well tolerated and showed trends towards improvement of clinical outcome measures. Tofacitinib was also tested in a proof-of-concept study for refractory dermatomyositis in which it significantly reduced disease activity, as well as serum CXCL9 and CXCL10 concentrations and the interferon gene signature in $\operatorname{skin}^{138}$. Baricitinib is similarly being evaluated in a phase II trial for patients with idiopathic inflammatory myositis ${ }^{139}$.

Table 3 | Anti-interferon therapies for autoimmune rheumatic diseases

\begin{tabular}{|c|c|c|c|c|}
\hline Drug & Disease & $\begin{array}{l}\text { Clinical } \\
\text { development }\end{array}$ & Status & Refs \\
\hline \multicolumn{5}{|l|}{ IFNa inhibitors } \\
\hline \multirow[t]{2}{*}{ Sifalimumab } & SLE & Phase II & Completed & 111 \\
\hline & $\mathrm{DM}$ and $\mathrm{PM}$ & Phase I & Completed & 114,115 \\
\hline Rontalizumab & SLE & Phase II & Completed & 112 \\
\hline IFNa kinoid & SLE & Phase II & Terminated & 118 \\
\hline \multicolumn{5}{|l|}{ IFNAR inhibitors } \\
\hline \multirow[t]{5}{*}{ Anifrolumab } & SLE & Phase III & Completed & $121-123$ \\
\hline & & Phase III & Ongoing & 151 \\
\hline & LN & Phase II & Ongoing & 124 \\
\hline & RA & Phase II & Ongoing & 125 \\
\hline & SSc & Phase I & Completed & 126,127 \\
\hline \multicolumn{5}{|l|}{ JAK inhibitors } \\
\hline \multirow[t]{5}{*}{ Tofacitinib } & SLE & Phase I & Completed & 135 \\
\hline & RA & Approved & NA & $152-155$ \\
\hline & pSS & Phase I/II & Ongoing & 136 \\
\hline & $\mathrm{SSc}$ & Phase I/II & Completed & 137 \\
\hline & DM & Phase I & Completed & 138 \\
\hline \multirow[t]{3}{*}{ Baricitinib } & SLE & Phase III & Ongoing & $130-133$ \\
\hline & RA & Approved & NA & $156-158$ \\
\hline & IIM & Phase II & Ongoing & 139 \\
\hline \multirow[t]{2}{*}{ Upadacitinib } & SLE & Phase II & Ongoing & 159 \\
\hline & RA & Approved & NA & $160-163$ \\
\hline \multicolumn{5}{|c|}{ Interferon production inhibitors } \\
\hline BlIB059 (anti-BDCA2) & SLE and CLE & Phase II & Completed & 145,146 \\
\hline VIB7734 (anti-LILR4A) & $\begin{array}{l}\text { SLE, CLE, pSS, } \\
\text { SSc, DM and PM }\end{array}$ & Phase I & Completed & 147 \\
\hline
\end{tabular}

BDCA2, blood dendritic cell antigen 2; CLE, cutaneous lupus erythematosus; DM, dermatomyositis; IFNAR, IFNa receptor; IIM, idiopathic inflammatory myositis; JAK, Janus kinase; LILR4A, leukocyte immunoglobulin-like receptor subfamily A member 4; LN, lupus nephritis; NA, not applicable; PM, polymyositis; pSS, primary Sjögren syndrome; RA, rheumatoid arthritis; SLE, systemic lupus erythematosus; SSc, systemic sclerosis.
Targeting interferon production. pDCs are a primary source of both type I and type III interferons in SLE. Depletion of pDCs in mouse models of lupus attenuates autoimmunity ${ }^{140-142}$, suggesting that targeting these cells might be an effective treatment option. Blood dendritic cell antigen 2 (BDCA2) is expressed specifically on pDCs and is a potent inhibitor of type I and type III interferon induction when ligated ${ }^{39,143}$. Notably, BDCA2 expression on pDCs from patients with SLE is decreased, and interferon production can be inhibited ex vivo by an anti-BDCA2 monoclonal antibody ${ }^{144}$. This approach was tested in a phase I trial for SLE. Treatment with BIIB059, an anti-BDCA2 monoclonal antibody, reduced ISG expression in peripheral blood and interferon-induced proteins in active skin lesions ${ }^{145}$. These findings were associated with improvements in cutaneous disease, as measured by the CLE Disease Area and Severity Index score, and were also associated with reduced CD45 $5^{+}$ immune cell infiltration into skin lesions. BIIB059 is still in development and has completed a phase II trial for SLE and CLE for which preliminary results have been announced $^{146}$.

Other biologic agents that target pDCs are also in development. VIB7734, an anti-leukocyte immunoglobulinlike receptor subfamily A member 4 (LILRA4) monoclonal antibody that targets pDCs for antibody-dependent cellular cytolysis, has completed a phase Ib trial in a variety of autoimmune diseases, including SLE, CLE, pSS, SSc, dermatomyositis and polymyositis ${ }^{147}$. Preliminary analysis of data in patients with CLE showed that VIB7734 significantly reduced pDCs in blood and skin, which corresponded with a decrease in interferon gene signature and improvement in CLE Disease Area and Severity Index score. Although these studies require further validation and did not discriminate between type I and type III interferons, the efficacy of anti-pDC therapies suggests that targeting upstream pathways could be advantageous over blocking type I interferons alone.

In addition to biologic agents that target BDCA2 or LILRA4, a variety of drugs can inhibit interferon production by other means. Antimalarial drugs such as hydroxychloroquine are commonly used to treat SLE and can inhibit type I and type III interferon production by pDCs in response to TLR7 or TLR9 stimulation ${ }^{77,148}$. Other TLR inhibitors are currently in various stages of development ${ }^{149}$.

\section{Conclusions}

Type I interferons are central to the immunopathology of rheumatic diseases and are an important target for therapeutic intervention. By contrast, type III interferons are a new addition to the interferon family that have specialized functions, particularly at barrier surfaces. Early reports suggested that unlike type I interferons, type III interferons seemed to limit inflammation and host damage; as such, type III interferons have not been a major focus of research in rheumatology. However, data indicate that type III interferons are not strictly pro-inflammatory or anti-inflammatory; rather, they seem to have context-dependent functions in regulating immune responses. In autoimmune diseases such as SLE, 
in which concentrations of IFN $\lambda$ s are abnormally elevated and their signalling is chronically activated, IFN $\lambda$ s might promote immune dysregulation and tissue inflammation. In other diseases in which the effects of IFN $\lambda$ s are more tightly regulated, endogenous or exogenously provided IFN $\lambda$ might have an immunoregulatory function that suppresses inflammation. Although this difference is better understood in the context of infectious disease, improved understanding of the context-dependent functions of IFN $\lambda$ s will be important to optimize treatment and management for patients with autoimmune rheumatic diseases.

Published online 27 April 2021
1. Lazear, H. M., Nice, T. J. \& Diamond, M. S. Interferon- $\lambda$ : immune functions at barrier surfaces and beyond Immunity 43, 15-28 (2015).

2. Wack, A., Terczynska-Dyla, E. \& Hartmann, R. Guarding the frontiers: the biology of type III interferons. Nat. Immunol. 16, 802-809 (2015).

3. Ye, L., Schnepf, D. $\&$ Staeheli, P. Interferon- $\lambda$ orchestrates innate and adaptive mucosal immune responses. Nat. Rev. Immunol. 19, 614-625 (2019).

4. Crow, M. K., Olferiev, M. \& Kirou, K. A. Type I interferons in autoimmune disease. Annu. Rev. Pathol. 14, 369-393 (2019).

5. Manthiram, K., Zhou, Q., Aksentijevich, I. \& Kastner, D. L. The monogenic autoinflammatory diseases define new pathways in human innate immunity and inflammation. Nat. Immunol. 18, 832-842 (2017)

6. Rodero, M. P. \& Crow, Y. J. Type I interferonmediated monogenic autoinflammation: The type interferonopathies, a conceptual overview. J. Exp. Med. 213, 2527-2538 (2016)

7. Ivashkiv, L. B. $\&$ Donlin, L. T. Regulation of type I interferon responses. Nat. Rev. Immunol. 14, 36-49 (2014).

8. Murphy, G. \& Isenberg, D. A. New therapies for systemic lupus erythematosus - past imperfect, future tense. Nat. Rev. Rheumatol. 15, 403-412 (2019).

9. Kotenko, S. V. \& Durbin, J. E. Contribution of type III interferons to antiviral immunity: location, location, location. J. Biol. Chem. 292, 7295-7303 (2017).

10. Prokunina-Olsson, L. et al. A variant upstream of IFNL3 (IL28B) creating a new interferon gene IFNL4 is associated with impaired clearance of hepatitis C virus. Nat. Genet. 45, 164-171 (2013).

11. Lasfar, A. et al. Characterization of the mouse IFNlambda ligand-receptor system: IFN-lambdas exhibit antitumor activity against B16 melanoma. Cancer Res. 66, 4468-4477 (2006)

12. Kotenko, S. V. et al. IFN-lambdas mediate antiviral protection through a distinct class II cytokine receptor complex. Nat. Immunol. 4, 69-77 (2003).

13. Sheppard, P. et al. IL-28, IL-29 and their class II cytokine receptor IL-28R. Nat. Immunol. 4, 63-68 (2003).

14. Schneider, W. M., Chevillotte, M. D. \& Rice, C. M. Interferon-stimulated genes: a complex web of host defenses. Annu. Rev. Immunol. 32, 513-545 (2014).

15. Klinkhammer, J. et al. IFN- $\lambda$ prevents influenza virus spread from the upper airways to the lungs and limits virus transmission. eLife 7, e33354 (2018).

16. Pervolaraki, K. et al. Differential induction of interferon stimulated genes between type I and type III interferons is independent of interferon receptor abundance. PLoS Pathog. 14, e 1007420 (2018).

17. Blumer, T., Coto-Llerena, M., Duong, F. H. T. \& Heim, M. H. SOCS1 is an inducible negative regulator of interferon $\lambda$ (IFN- $\lambda$ )-induced gene expression in vivo. J. Biol. Chem. 292, 17928-17938 (2017).

18. Burkart, C. et al. Usp18 deficient mammary epithelial cells create an antitumour environment driven by hypersensitivity to IFN- $\lambda$ and elevated secretion of Cxcl10. EMBO Mol Med 5, 1035-1050 (2013).

19. Francois-Newton, V. et al. USP18-based negative feedback control is induced by type I and type III interferons and specifically inactivates interferon alpha response. PLOS ONE 6, e22200 (2011).

20. Mahlakoiv, T., Hernandez, P., Gronke, K., Diefenbach, A $\S$ Staeheli, P. Leukocyte-derived IFN- $\alpha / \beta$ and epithelial IFN- $\lambda$ constitute a compartmentalized mucosal defense system that restricts enteric virus infections. PLoS Pathog. 11, e1004782 (2015).

21. Nice, T. J. et al. Interferon- $\lambda$ cures persistent murine norovirus infection in the absence of adaptive immunity. Science 347, 269-273 (2015).

22. Lin, J. D. et al. Distinct roles of type I and type III Interferons in intestinal immunity to homologous and heterologous rotavirus infections. PLoS Pathog. 12, e1005600 (2016)

23. Baldridge, M. T. et al. Expression of IfnIr 1 on intestinal epithelial cells is critical to the antiviral effects of interferon lambda against norovirus and reovirus. J. Virol. 91, e02079-16 (2017).

24. Caine, E. A. et al. Interferon lambda protects the female reproductive tract against Zika virus infection. Nat. Commun. 10, 280 (2019).

25. Galani, I. E. et al. Interferon- $\lambda$ mediates non-redundant front-line antiviral protection against influenza virus infection without compromising host fitness. Immunity 46, 875-890.e6 (2017).

26. Lazear, H. M. Schoggins, J. W. \& Diamond, M. S Shared and distinct functions of type I and type III interferons. Immunity 50, 907-923 (2019).

27. Forero, A. et al. Differential activation of the transcription factor IRF1 underlies the distinct immune responses elicited by type I and type II interferons. Immunity 51, 451-464.e6 (2019).

28. Broggi, A., Tan, Y., Granucci, F. \& Zanoni, I. IFN- $\lambda$ suppresses intestinal inflammation by non-translational regulation of neutrophil function. Nat. Immunol. 18, 1084-1093 (2017).

29. Alase, A. A. et al. IFN $\lambda$ stimulates MxA production in human dermal fibroblasts via a MAPK-dependen STAT 1-independent mechanism. J. Invest. Dermatol. 135, 2935-2943 (2015)

30. Lazear, H. M et al Interferon- $\lambda$ restricts West Nile virus neuroinvasion by tightening the blood-brain barrier. Sci. Transl Med. 7, 284 ra259 (2015)

31. Zanoni, I., Granucci, F. \& Broggi, A. Interferon (IFN)- $\lambda$ takes the helm: immunomodulatory roles of type III IFNs. Front. Immunol. 8, 1661 (2017).

32. Blazek, K. et al. IFN- $\lambda$ resolves inflammation via suppression of neutrophil infiltration and IL-1 $\beta$ production. J. Exp. Med. 212, 845-853 (2015).

33. Espinosa, V. et al. Type III interferon is a critical regulator of innate antifungal immunity. Sci. Immunol. 2, eaan5357 (2017)

34. Chrysanthopoulou, A. et al. Interferon lambda $1 /$ IL-29 and inorganic polyphosphate are novel regulators of neutrophil-driven thromboinflammation. J. Pathol. 243, 111-122 (2017).

35. Goel, R. R. et al. Interferon lambda promotes immune dysregulation and tissue inflammation in TLR7-induced lupus. Proc. Natl Acad. Sci. USA 117, 5409-5419 (2020).

36. Santer, D. M. et al. Differential expression of interferon-lambda receptor 1 splice variants determines the magnitude of the antiviral response induced by interferon-lambda 3 in human immune cells. PLoS Pathog. 16, e 1008515 (2020).

37. Finotti, G., Tamassia, N., Calzetti, F., Fattovich, G. $\&$ Cassatella, M. A. Endogenously produced TNF- $\alpha$ contributes to the expression of CXCL10/IP-10 in IFN- $\lambda 3$-activated plasmacytoid dendritic cells. J. Leukoc. Biol. 99, 107-119 (2016).

38. Finotti, G. Tamassia, N. \& Cassatella, M. A. Synergistic production of TNF $\alpha$ and IFN $\alpha$ by human pDCs incubated with IFN $\lambda 3$ and IL-3. Cytokine 86, 124-131 (2016)

39. Yin, Z. et al. Type III IFNs are produced by and stimulate human plasmacytoid dendritic cells. J. Immunol. 189, 2735-2745 (2012)

40. Mennechet, F. J. \& Uze, G. Interferon-lambda-treated dendritic cells specifically induce proliferation of FOXP3-expressing suppressor T cells. Blood 107 4417-4423 (2006).

41 Jordan, W. J et al. Human interferon lambda-1 (IFN-lambda1/IL-29) modulates the Th1/Th2 response. Genes. Immun. 8, 254-261 (2007).

42. Koltsida, O. et al. IL-28A (IFN- $\lambda 2$ ) modulates lung DC function to promote Th1 immune skewing and suppress allergic airway disease. EMBO Mol. Med. 3 348-361 (2011)

43. Read, S. A. et al. Macrophage coordination of the interferon lambda immune response. Front. Immunol. 10, 2674 (2019).
44. Hou, W. et al. Lambda interferon inhibits human immunodeficiency virus type 1 infection of macrophages. J. Virol. 83, 3834-3842 (2009).

45. Liu, B. S., Janssen, H. L. \& Boonstra, A. IL-29 and IFN $a$ differ in their ability to modulate IL-12 production by TLR-activated human macrophages and exhibit differential regulation of the IFN $\gamma$ receptor expression. Blood 117, 2385-2395 (2011).

46. Liu, M. Q. et al. IFN- $\lambda 3$ inhibits HIV infection of macrophages through the JAK-STAT pathway. PLOS ONE 7, e35902 (2012).

47. Morrison, M. H. et al. IFNL cytokines do not modulate human or murine NK cell functions. Hum. Immunol. 75, 996-1000 (2014).

48. de Groen, R. A. et al. IFN- $\lambda$-mediated IL-12 production in macrophages induces IFN- $\gamma$ production in human NK cells. Eur. J. Immunol. 45, 250-259 (2015).

49. Wang, Y. et al. Involvement of NK cells in IL-28Bmediated immunity against influenza virus infection. J. Immunol. 199, 1012-1020 (2017).

50. Ank, N. et al. An important role for type III interferon (IFN-lambda/IL-28) in TLR-induced antiviral activity. J. Immunol. 180, 2474-2485 (2008).

51. Ye, L. et al. Interferon- $\lambda$ enhances adaptive mucosal immunity by boosting release of thymic stromal lymphopoietin. Nat. Immunol. 20, 593-601 (2019).

52. Misumi, I. $\&$ Whitmire, J. K. IFN- $\lambda$ exerts opposing effects on $\mathrm{T}$ cell responses depending on the chronicity of the virus infection. J. Immunol. 192, 3596-3606 (2014).

53. Kelly, A. et al. Immune cell profiling of IFN- $\lambda$ response shows $\mathrm{pDC}$ express highest level of IFN- $\lambda \mathrm{R} 1$ and are directly responsive via the JAK-STAT pathway. J. Interferon Cytokine Res. 36, 671-680 (2016).

54. de Groen, R. A., Groothuismink, Z. M., Liu, B. S. \& Boonstra, A. IFN- $\lambda$ is able to augment TLR-mediated activation and subsequent function of primary human B cells. J. Leukoc. Biol. 98, 623-630 (2015).

55. Syedbasha, M. et al. Interferon- $\lambda$ enhances the differentiation of naive $B$ cells into plasmablasts via the mTORC1 pathway. Cell Rep. 33, 108211 (2020).

56. Egli, A. et al. IL-28B is a key regulator of B- and T-cell vaccine responses against influenza. PLoS Pathog. 10 e 1004556 (2014).

57. Jordan, W. J. et al. Modulation of the human cytokine response by interferon lambda-1 (IFN-lambda1/IL-29) Genes. Immun. 8, 13-20 (2007)

58. Hemann, E. A. et al. Interferon- $\lambda$ modulates dendritic cells to facilitate $T$ cell immunity during infection with influenza A virus. Nat. Immunol. 20, 1035-1045 (2019).

59. Baechler, E. C. et al. Interferon-inducible gene expression signature in peripheral blood cells of patients with severe lupus. Proc. Natl Acad. Sci. USA 100, 2610-2615 (2003).

60. Bennett, L. et al. Interferon and granulopoiesis signatures in systemic lupus erythematosus blood. J. Exp. Med. 197, 711-723 (2003).

61. Der, E. et al. Tubular cell and keratinocyte single-cell transcriptomics applied to lupus nephritis reveal type I IFN and fibrosis relevant pathways. Nat. Immunol. 20, 915-927 (2019)

62. Crow, M. K. Type I interferon in the pathogenesis of lupus. J. Immunol. 192, 5459-5468 (2014).

63. Wu, Q., Yang, Q., Lourenco, E., Sun, H. \& Zhang, Y. Interferon-lambda1 induces peripheral blood mononuclear cell-derived chemokines secretion in patients with systemic lupus erythematosus: its correlation with disease activity. Arthritis Res. Ther 13, R88 (2011)

64. Adel, Y. \& Sadeq, Y. Impact of IL-34, IFN- $\alpha$ and IFN- $\lambda$ I on activity of systemic lupus erythematosus in Egyptian patients. Reumatologia 58, 221-230 (2020).

65. Amezcua-Guerra, L. M. et al. Type III interferons in systemic lupus erythematosus: association between interferon $\lambda 3$, disease activity, and anti-Ro/SSA antibodies. J. Clin. Rheumatol. 23, 368-375 (2017). 
66. Chen, J. Y. et al. Interferon- $\lambda 3 / 4$ genetic variants and interferon- $\lambda 3$ serum levels are biomarkers of lupus nephritis and disease activity in Taiwanese. Arthritis Res. Ther. 20, 193 (2018)

67. Oke, V. et al. IFN- $\lambda 1$ with Th 17 axis cytokines and IFN- $\alpha$ define different subsets in systemic lupus erythematosus (SLE). Arthritis Res. Ther 19,139 (2017).

68. Oke, V. et al. High levels of circulating interferons type I, type II and type III associate with distinct clinical features of active systemic lupus erythematosus. Arthritis Res. Ther. 21, 107 (2019).

69. Zahn, S. et al. Evidence for a pathophysiological role of keratinocyte-derived type III interferon (IFN $\lambda$ ) in cutaneous lupus erythematosus. J. Invest. Dermatol. 131, 133-140 (2011)

70. Zickert, A. et al. Interferon (IFN)- $\lambda$ is a potentia mediator in lupus nephritis. Lupus Sci. Med. 3 e000170 (2016)

71. Hu, F. Q. et al. Characterization of autoantibodies and cytokines related to cutaneous lupus erythematosus. Lupus 30, 315-319 (2021).

72. Lin, S. C., Kuo, C. C., Tsao, J. T. \& Lin, L. J. Profiling the expression of interleukin (IL)-28 and IL-28 receptor $\alpha$ in systemic lupus erythematosus patients. Eur. J. Clin. Invest. 42, 61-69 (2012).

73. Li, Y. et al. Association analyses identifying two common susceptibility loci shared by psoriasis and systemic lupus erythematosus in the Chinese Han population. J. Med. Genet. 50, 812-818 (2013).

74. Blanco, P. et al. Increase in activated CD8 lymphocytes expressing perforin and granzyme $B$ correlates with disease activity in patients with systemic lupus erythematosus. Arthritis Rheum. 52 , 201-211 (2005)

75. Sommereyns, C., Paul, S., Staeheli, P. \& Michiels, T. IFN-lambda (IFN-lambda) is expressed in a tissuedependent fashion and primarily acts on epithelial cells in vivo. PLoS Pathog. 4, e1000017 (2008)

76. Panda, S. K., Kolbeck, R. \& Sanjuan, M. A. Plasmacytoid dendritic cells in autoimmunity. Curr. Opin. Immunol. 44, 20-25 (2017).

77. Hjorton, K., Hagberg, N., Pucholt, P., Eloranta, M. L. $\S$ Ronnblom, L. The regulation and pharmacological modulation of immune complex induced type III IFN production by plasmacytoid dendritic cells. Arthritis Res. Ther. 22, 130 (2020)

78. Goel, R. R. \& Kaplan, M. J. Deadliest catch: neutrophil extracellular traps in autoimmunity. Curr. Opin. Rheumatol. 32, 64-70 (2020)

79. Lood, C. et al. Neutrophil extracellular traps enriched in oxidized mitochondrial DNA are interferogenic and contribute to lupus-like disease. Nat. Med. 22, 146-153 (2016)

80. Scholtissek, B. et al. Immunostimulatory endogenous nucleic acids drive the lesional inflammation in cutaneous lupus erythematosus. J. Invest. Dermatol. 137, 1484-1492 (2017).

81. Wenzel, J. Cutaneous lupus erythematosus: new insights into pathogenesis and therapeutic strategies. Nat. Rev. Rheumatol. 15, 519-532 (2019).

82. Guo, Q. et al. Rheumatoid arthritis: pathological mechanisms and modern pharmacologic therapies. Bone Res. 6, 15 (2018).

83. Lubbers, J. et al. The type I IFN signature as a biomarker of preclinical rheumatoid arthritis. Ann. Rheum. Dis. 72, 776-780 (2013).

84. Lande, R. et al. Characterization and recruitment of plasmacytoid dendritic cells in synovial fluid and tissue of patients with chronic inflammatory arthritis. J. Immunol. 173, 2815-2824 (2004).

85. van Holten, J., Smeets, T. J., Blankert, P \& Tak, P. P. Expression of interferon beta in synovial tissue from patients with rheumatoid arthritis: comparison with patients with osteoarthritis and reactive arthritis. Ann. Rheum. Dis. 64, 1780-1782 (2005).

86. $\mathrm{Wu}, \mathrm{Q}$. et al. Serum IFN- $\lambda 1$ is abnormally elevated in rheumatoid arthritis patients. Autoimmunity 46 40-43 (2013)

87. Castillo-Martinez, D. et al. Type-III interferons and rheumatoid arthritis: Correlation between interferon lambda 1 (interleukin 29) and antimutated citrullinated vimentin antibody levels. Autoimmunity 50, 82-85 (2017).

88. Wang, F. et al. Interleukin-29 modulates proinflammatory cytokine production in synovial inflammation of rheumatoid arthritis. Arthritis Res. Ther. 14, R228 (2012).

89. Chang, Q. J., Lv, C., Zhao, F., Xu, T. S. \& Li, P. Elevated serum levels of interleukin-29 are associated with disease activity in rheumatoid arthritis patients with anti-cyclic citrullinated peptide antibodies. Tohoku J. Exp. Med. 241, 89-95 (2017).

90. Xu, L. et al. IL-29 enhances Toll-like receptor-mediated IL- 6 and IL- 8 production by the synovial fibroblasts from rheumatoid arthritis patients. Arthritis Res. Ther. 15, R170 (2013)

91. Chen, $Y$ et al. Dendritic cells-derived interferon- $\lambda 1$ ameliorated inflammatory bone destruction through inhibiting osteoclastogenesis. Cell Death Dis. 11, 414 (2020).

92. Gottenberg, J. E. et al. Activation of IFN pathways and plasmacytoid dendritic cell recruitment in target organs of primary Sjögren's syndrome. Proc. Natl Acad. Sci. USA 103, 2770-2775 (2006).

93. Hjelmervik, T. O., Petersen, K., Jonassen, I. Jonsson, R. \& Bolstad, A. I. Gene expression profiling of minor salivary glands clearly distinguishes primary Sjögren's syndrome patients from healthy control subjects. Arthritis Rheum. 52, 1534-1544 (2005).

94. Apostolou, E. et al. Expression of type III interferons (IFN $\lambda$ s) and their receptor in Sjögren's syndrome. Clin. Exp. Immunol. 186, 304-312 (2016).

95. Ha, Y. J. et al. Increased expression of interferon- $\lambda$ in minor salivary glands of patients with primary Sjögren's syndrome and its synergic effect with interferon-alpha on salivary gland epithelial cells. Clin. Exp. Rheumatol 36, 31-40 (2018).

96. Dantas, A. T. et al. Interferons and systemic sclerosis: correlation between interferon gamma and interferon lambda 1 (IL-29). Autoimmunity 48, 429-433 (2015).

97. Metwally, M. et al. IFNL3 genotype is associated with pulmonary fibrosis in patients with systemic sclerosis. Sci. Rep. 9, 14834 (2019)

98. Haasnoot, A. M. et al. Ocular fluid analysis in children reveals interleukin-29/interferon- $\lambda 1$ as a biomarke for juvenile idiopathic arthritis-associated uveitis. Arthritis Rheumatol. 68, 1769-1779 (2016).

99. Wolk, K. et al. IL-29 is produced by $T_{H} 17$ cells and mediates the cutaneous antiviral competence in psoriasis. Sci. Transl Med. 5, 204 ra 129 (2013).

100. Chiriac, M. T. et al. Activation of epithelial signal transducer and activator of transcription 1 by interleukin 28 controls mucosal healing in mice with colitis and is increased in mucosa of patients with inflammatory bowel disease. Gastroenterology 153 123-138.e8 (2017).

101. Broggi, A. et al. Type III interferons disrupt the lung epithelial barrier upon viral recognition. Science 369 706-712 (2020)

102. Major, J. et al. Type I and III interferons disrupt lung epithelial repair during recovery from viral infection. Science 369, 712-717 (2020).

103. Duong, F. H. et al. IFN- $\lambda$ receptor 1 expression is induced in chronic hepatitis $\mathrm{C}$ and correlates with the IFN- $\lambda 3$ genotype and with nonresponsiveness to IFN-a therapies. J. Exp. Med. 211, 857-868 (2014).

104. Syedbasha, M. et al. An ELISA based binding and competition method to rapidly determine ligandreceptor interactions. J. Vis. Exp. 14, 53575 (2016).

105. Dellgren, C., Gad, H. H., Hamming, O. J. Melchjorsen, J. \& Hartmann, R. Human interferonlambda3 is a potent member of the type III interferon family. Genes. Immun. 10, 125-131 (2009).

106. Diegelmann, J. et al. Comparative analysis of the lambda-interferons IL-28A and IL-29 regarding their transcriptome and their antiviral properties against hepatitis C virus. PLoS ONE 5, e15200 (2010).

107. Benhammadi, M. et al. IFN- $\lambda$ enhances constitutive expression of MHC class I molecules on thymic epithelial cells. J. Immunol. 205, 1268-1280 (2020).

108. Dinnon, K. H. III et al. A mouse-adapted model of SARS-CoV-2 to test COVID-19 countermeasures. Nature 586, 560-566 (2020).

109. Flisiak, R. et al. A randomized study of peginterferon lambda-1 a compared to peginterferon alfa- $2 a$ in combination with ribavirin and telaprevir in patients with genotype-1 chronic hepatitis C. PLOS ONE 11, e0164563 (2016)

110. Muir, A. J. et al. A randomized phase $2 \mathrm{~b}$ study of peginterferon lambda- $1 \mathrm{a}$ for the treatment of chronic HCV infection. J. Hepatol. 61, 1238-1246 (2014).

111. Khamashta, M. et al. Sifalimumab, an anti-interferonmonoclonal antibody, in moderate to severe systemic lupus erythematosus: a randomised, double-blind, placebo-controlled study. Ann. Rheum. Dis. 75 1909-1916 (2016).

112. Kalunian, K. C. et al. A phase II study of the efficacy and safety of rontalizumab (rhuMAb interferon- $\alpha$ ) in patients with systemic lupus erythematosus (ROSE). Ann. Rheum. Dis. 75, 196-202 (2016).
113. Isenberg, D. A. \& Merrill, J. T. Why, why, why de-lupus (does so badly in clinical trials). Expert. Rev. Clin. Immunol. 12, 95-98 (2016).

114. Higgs, B. W. et al. A phase $1 \mathrm{~b}$ clinical trial evaluating sifalimumab, an anti-IFN- $\alpha$ monoclonal antibody, shows target neutralisation of a type I IFN signature in blood of dermatomyositis and polymyositis patients. Ann. Rheum. Dis. 73, 256-262 (2014).

115. Guo, X. et al. Suppression of soluble T cell-associated proteins by an anti-interferon- $\alpha$ monoclonal antibody in adult patients with dermatomyositis or polymyositis. Rheumatology 53, 686-695 (2014).

116. Lauwerys, B. R. et al. Down-regulation of interferon signature in systemic lupus erythematosus patients by active immunization with interferon $\alpha$-kinoid. Arthritis Rheum. 65, 447-456 (2013).

117. Ducreux, J. et al. Interferon a kinoid induces neutralizing anti-interferon $\alpha$ antibodies that decrease the expression of interferon-induced and $B$ cell activation associated transcripts: analysis of extended follow-up data from the interferon a kinoid phase I/II study. Rheumatology 55, 1901-1905 (2016).

118. Houssiau, F. A. et al. IFN- $\alpha$ kinoid in systemic lupus erythematosus: results from a phase Ilb, randomised placebo-controlled study. Ann. Rheum. Dis. 79 347-355 (2020).

119. Bastard, P. et al. Autoantibodies against type I IFNs in patients with life-threatening COVID-19. Science $\mathbf{3 7 0}$, eabd4585 (2020).

120. Huang, J. et al. Inhibition of type I and type III interferons by a secreted glycoprotein from Yaba-like disease virus. Proc. Natl Acad. Sci. USA 104 9822-9827 (2007).

121. Furie, R. A. et al. Type I interferon inhibitor anifrolumab in active systemic lupus erythematosus (TULIP-1): a randomised, controlled, phase 3 trial. Lancet Rheumatol. 1, e208-e219 (2019).

122. Morand, E. F. et al. Trial of anifrolumab in active systemic lupus erythematosus. N. Engl. J. Med. 382, 211-221 (2020)

123. Casey, K. A. et al. Modulation of cardiometabolic disease markers by type I interferon inhibition in systemic lupus erythematosus. Arthritis Rheumatol. 73, 459-471 (2020)

124. US National Library of Medicine. ClinicalTrials.gov https://www.clinicaltrials.gov/ct2/show/NCT02547922 (2021).

125. US National Library of Medicine. ClinicalTrials.gov https://www.clinicaltrials.gov/ct2/show/NCT03435601 (2020).

126. Goldberg, A. et al. Dose-escalation of human antiinterferon- $\alpha$ receptor monoclonal antibody MEDI-546 in subjects with systemic sclerosis: a phase 1 , multicenter, open label study. Arthritis Res. Ther. 16, R57 (2014).

127. Guo, X. et al. Suppression of T cell activation and collagen accumulation by an anti-IFNAR $1 \mathrm{mAb}$, anifrolumab, in adult patients with systemic sclerosis. J. Invest. Dermatol. 135, 2402-2409 (2015).

128. Gadina, M. et al. Translational and clinical advances in JAK-STAT biology: the present and future of jakinibs. J. Leukoc. Biol. 104, 499-514 (2018).

129. Schwartz, D. M. et al. JAK inhibition as a therapeutic strategy for immune and inflammatory diseases. Nat. Rev. Drug Discov. 16, 843-862 (2017)

130. Wallace, D. J. et al. Baricitinib for systemic lupus erythematosus: a double-blind, randomised, placebocontrolled, phase 2 trial. Lancet 392, 222-231 (2018).

131. US National Library of Medicine. ClinicalTrials.gov https://www.clinicaltrials.gov/ct2/show/NCT03616912 (2021).

132. US National Library of Medicine. ClinicalTrials.gov https://www.clinicaltrials.gov/ct2/show/NCT03616964 (2021).

133. US National Library of Medicine. ClinicalTrials.gov https://www.clinicaltrials. gov/ct2/show/NCT03843125 (2021).

134. Furumoto, Y. et al. Tofacitinib ameliorates murine lupus and its associated vascular dysfunction. Arthritis Rheumatol. 69, 148-160 (2017).

135. Hasni, S. et al. $183 \mathrm{~A}$ phase $1 \mathrm{~B} / 2 \mathrm{~A}$ trial of tofacitinib an oral janus kinase inhibitor, in systemic lupus erythematosus [abstract]. Lupus Sci. Med. 6, A139 (2019).

136. US National Library of Medicine. ClinicalTrials.gov https://www.clinicaltrials.gov/ct2/show/NCT04496960 (2021).

137. US National Library of Medicine. ClinicalTrials.gov https://www.clinicaltrials.gov/ct2/show/NCT03274076 (2020) 
138. Paik, J. J. et al. Study of tofacitinib in refractory dermatomyositis (STIR): an open label pilot study of 10 patients. Arthritis Rheumatol. https://doi.org/ 10.1002/art.41602 (2020).

139. US National Library of Medicine. ClinicalTrials.gov https://www.clinicaltrials.gov/ct2/show/NCT04208464 (2019).

140. Rowland, S. L. et al. Early, transient depletion of plasmacytoid dendritic cells ameliorates autoimmunity in a lupus model. J. Exp. Med. 211, 1977-1991 (2014).

141. Sisirak, V. et al. Genetic evidence for the role of plasmacytoid dendritic cells in systemic lupus erythematosus. J. Exp. Med. 211, 1969-1976 (2014).

142. Yokogawa, M. et al. Epicutaneous application of Toll-like receptor 7 agonists leads to systemic autoimmunity in wild-type mice: a new model of systemic lupus erythematosus. Arthritis Rheumatol. 66, 694-706 (2014)

143. Dzionek, A. et al. BDCA-2, a novel plasmacytoid dendritic cell-specific type II C-type lectin, mediates antigen capture and is a potent inhibitor of interferon alpha/beta induction. J. Exp. Med. 194, 1823-1834 (2001).

144. Blomberg, S., Eloranta, M. L., Magnusson, M., Alm, G. V. \& Ronnblom, L. Expression of the markers BDCA-2 and BDCA-4 and production of interferonalpha by plasmacytoid dendritic cells in systemic lupus erythematosus. Arthritis Rheum. 48, 2524-2532 (2003).

145. Furie, R. et al. Monoclonal antibody targeting BDCA2 ameliorates skin lesions in systemic lupus erythematosus. J. Clin. Invest. 129, 1359-1371 (2019).

146. Werth, V. et al. OP0193 BIIB059, a humanized monoclonal antibody targeting BDCA2 on plasmacytoid dendritic cells ( $\mathrm{pDC}$ ), shows dose-related efficacy in the phase 2 LILAC study in patients (pts) with active cutaneous lupus erythematosus (CLE) [abstract]. Ann. Rheum. Dis. 79, 120-121 (2020).

147. US National Library of Medicine. ClinicalTrials.gov https://www.clinicaltrials.gov/ct2/show/NCT03817424 (2020).

148. Schrezenmeier, E. \& Dorner, T. Mechanisms of action of hydroxychloroquine and chloroquine: implications for rheumatology. Nat. Rev. Rheumatol. 16, 155-166 (2020).
149. Smith, N. et al. Control of TLR7-mediated type I IFN signaling in pDCs through CXCR4 engagement - a new target for lupus treatment. Sci. Adv. 5, eaav9019 (2019).

150. Selvakumar, T. A. et al. Identification of a predominantly interferon- $\lambda$-induced transcriptional profile in murine intestinal epithelial cells. Front Immunol. 8, 1302 (2017).

151. US National Library of Medicine. ClinicalTrials.gov https://www.clinicaltrials.gov/ct2/show/NCT02794285 (2021).

152. Fleischmann, R. et al. Placebo-controlled trial of tofacitinib monotherapy in rheumatoid arthritis. N. Engl. J. Med. 367, 495-507 (2012).

153. van Vollenhoven, R. F. et al. Tofacitinib or adalimumab versus placebo in rheumatoid arthritis. N. Engl. J. Med. 367, 508-519 (2012).

154. Lee, E. B. et al. Tofacitinib versus methotrexate in rheumatoid arthritis. N. Engl. J. Med. 370 , 2377-2386 (2014).

155. Fleischmann, R. et al. Efficacy and safety of tofacitinib monotherapy, tofacitinib with methotrexate, and adalimumab with methotrexate in patients with rheumatoid arthritis (ORAL Strategy): a phase $3 \mathrm{~b} / 4$, double-blind, head-to-head, randomised controlled trial. Lancet 390, 457-468 (2017).

156. Genovese, M. C. et al. Baricitinib in patients with refractory rheumatoid arthritis. N. Engl. J. Med. 374 1243-1252 (2016).

157. Taylor, P. C. et al. Baricitinib versus placebo or adalimumab in rheumatoid arthritis. N. Engl. J. Med. 376, 652-662 (2017).

158. Fleischmann, R. et al. Baricitinib, methotrexate, or combination in patients with rheumatoid arthritis and no or limited prior disease-modifying antirheumatic drug treatment. Arthritis Rheumatol. 69, 506-517 (2017).

159. US National Library of Medicine. ClinicalTrials.gov https://www.clinicaltrials.gov/ct2/show/NCT03978520 (2021).

160. Rubbert-Roth, A. et al. Trial of upadacitinib or abatacept in rheumatoid arthritis. N. Engl. J. Med. 383, 1511-1521 (2020)

161. Burmester, G. R. et al. Safety and efficacy of upadacitinib in patients with rheumatoid arthritis and inadequate response to conventional synthetic diseasemodifying anti-rheumatic drugs (SELECT-NEXT): a randomised, double-blind, placebo-controlled phase 3 trial. Lancet 391, 2503-2512 (2018).

162. Genovese, M. C. et al. Safety and efficacy of upadacitinib in patients with active rheumatoid arthritis refractory to biologic disease-modifying anti-rheumatic drugs (SELECT-BEYOND): a doubleblind, randomised controlled phase 3 trial. Lancet 391, 2513-2524 (2018)

163. Smolen, J. S. et al. Upadacitinib as monotherapy in patients with active rheumatoid arthritis and inadequate response to methotrexate (SELECT MONOTHERAPY): a randomised, placebo-controlled, double-blind phase 3 study. Lancet 393, 2303-2311 (2019).

\section{Acknowledgements}

The work of R.R.G. and M.J.K. was supported by the Intramural Research Program at the National Institute of Arthritis and Musculoskeletal and Skin Diseases and the US National Institutes of Health.

\section{Author contributions}

R.R.G. and M.J.K. researched data for the article. All authors contributed substantially to discussion of the content. R.R.G. and M.J.K. wrote the article. All authors reviewed and/or edited the manuscript before submission.

\section{Competing interests}

The authors declare no competing interests. The National Institute of Arthritis and Musculoskeletal and Skin Diseases has collaborative research agreements with Medimmune/ AstraZeneca and Pfizer that pertain to anti-interferon therapies and Janus kinase inhibitors, respectively.

\section{Peer review information}

Nature Reviews Rheumatology thanks J.-Y. Chen and R. Hartmann for their contribution to the peer review of this work

\section{Publisher's note}

Springer Nature remains neutral with regard to jurisdictional claims in published maps and institutional affiliations.

This is a U.S. government work and not under copyright protection in the U.S.; foreign copyright protection may apply 2021 